\title{
How Should Retailers Deal with Consumer Sabotage of a Manufacturer Brand?
}

\author{
BETTINA NYFFENEGGER, ANDREA KÄHR, HARLEY KROHMER, AND WAYNE D. HOYER
}

\begin{abstract}
In the context of retail branding, the recently identified and conceptualized phenomenon of consumer brand sabotage (CBS) has become highly relevant as CBS does not only harm targeted manufacturer brands but also related retailer brands. Whereas the necessity of a managerial response to CBS seems evident, finding the most effective retailer response appears to be more complex. This article examines potential negative spillover effects from a sabotaged manufacturer brand on the respective retailer. Furthermore, it studies outcomes of different response strategies of retailers and takes important contingency factors (i.e., type of CBS and retailer's assortment size) and process variables (i.e., fairness perceptions) into account. Based on two large-scale online experiments, this article reveals negative spillover effects from a sabotaged manufacturer brand on the retailer brand and that an adequate response of the retailer (i.e., delisting vs. continuing to carry the brand) can decrease this effect, depending on contingency factors.
\end{abstract}

$\square$ uring the election of President Donald Trump, one consumer started the campaign \#GrabYourWallet, which encouraged shoppers to boycott brands with ties to Trump and his family. The boycott was a response to the leak of a conversation between Donald Trump and Billy Bush, wherein Trump made lewd comments about how he treats women. Initiated by a single consumer, this social media campaign achieved enormous reach. On Twitter alone, there were more than 626 million impressions of other consumers expressing their outrage about Trump's lewd conversation. The campaign has particularly targeted Ivanka Trump's clothing and shoe brand, which was carried by many retailers such as Nordstrom, Macy's, Amazon, and Zappos (Taylor 2017). While Macy's and other department store chains did not react to the \#GrabYourWallet campaign, Nordstrom announced amid this campaign to drop Ivanka Trump's brand from its assortment (officially stating that it discontinued the brand due to decreasing sales).

This example illustrates a relatively new phenomenon in which consumers, empowered by new technologies and driven by negative experiences or associations with a brand, become hostile and engage in aggressive activities that deliberately try to harm the brand. Kähr et al. (2016) have con- ceptualized this phenomenon as consumer brand sabotage (CBS), which is an attempt by consumers to harm a brand through the impairment of the brand-related associations of other consumers. A brand saboteur carefully plans and often invests a high level of effort to change other consumers' association and attitude toward the offending brand (Kähr et al. 2016). Thus, CBS is a form of hostile aggression that is more harmful than other forms of negative consumer behavior such as customer revenge, where consumers try to punish brands to "get even" (Bechwati and Morrin 2003; Grégoire, Laufer, and Tripp 2010). CBS can have a substantial negative impact on brands. For example, the YouTube video "United Breaks Guitars" caused United Airlines an estimated damage of more than $\$ 180$ million (Gulliver 2009), and the viral campaign \#FitchtheHomeless contributed to the dismissal of the CEO and a strong drop in share value of Abercrombie \& Fitch (Peterson 2014; Trefis Team 2014).

Given its high damage potential, a key question is how farreaching the impact of a CBS activity can be and whether this harm may even spill over to a retailer that carries the attacked brand. For example, the sabotage of the Ivanka Trump brand could indirectly cause damage to a related retailer (e.g., Nordstrom). In order to answer this question, this article examines

Bettina Nyffenegger (nyffenegger@imu.unibe.ch) is assistant professor of marketing, Andrea Kähr (kaehr@imu.unibe.ch) is a postdoctoral researcher of marketing, and Harley Krohmer (krohmer@imu.unibe.ch) is professor of marketing and chairman of the Marketing Department, all at the Institute of Marketing and Management, University of Bern, Switzerland. Wayne D. Hoyer (wayne.hoyer@mccombs.utexas.edu) is James L. Bayless/William S. Farish Fund Chair for Free Enterprise and chairman of the Department of Marketing, McCombs School of Business, University of Texas at Austin. The authors thank the editors and the review team for their insightful and constructive comments on this article.

JACR, volume 3, number 3. Published online July 9, 2018. http://dx.doi.org/10.1086/698875

(C) 2018 the Association for Consumer Research. All rights reserved. 2378-1815/2018/0303-0066\$10.00 
potential negative spillover effects of a sabotaged manufacturer brand on the retailer that carries the brand. Prior studies that examined the interdependence between manufacturer and retailer brands have generally focused on a positive image transfer. For example, Jacoby and Mazursky (1984) studied how the quality image of a manufacturer brand positively influences consumers' image of the retailer. However, missing from the literature is an examination of whether and how a sabotaged brand will affect the retailer that carries it.

Furthermore, a critical challenge for the retailer is how to respond to this situation. In light of this, the goal of the current study is to analyze the outcomes of different response strategies to a sabotaged brand (i.e., delisting vs. continuing to carry the brand). In a digital age where consumers can harm a brand with relatively little effort, such response strategies become increasingly important, especially for retailers. While a manufacturer has to monitor and potentially respond to sabotage activities toward its own brand, a retailer is likely to face the CBS phenomenon more frequently, as it carries many brands that could become victims of CBS. However, despite its high relevance, no research has yet addressed whether and how retailers should react to negative spillover effects (e.g., caused by CBS) from manufacturer brands on their own brand and how this decision may be influenced by context factors.

Against this background, we address three key research questions: (1) How does consumer sabotage of a manufacturer brand influence other consumers' attitude toward the retailer that carries the brand? (2) Can a potential negative spillover effect be prevented by delisting the manufacturer brand, or should a retailer continue to carry the sabotaged brand? (3) Which factors moderate the impact of the retailer's response on other consumers' attitude toward the retailer? More specifically, what roles do the stimulus that provoked the CBS activity (i.e., based on performance failures vs. based on a value conflict) and the characteristics of the retailer such as the size of its assortment play?

In answering these research questions, we make several important contributions to the literature. First, while a prior study has examined what drives consumers to engage in such hostile behavior toward a brand (Kähr et al. 2016), we take a different perspective and are particularly interested in the damage that CBS can cause to a brand in the minds of other consumers. Thus, rather than examining the dyadic relationship between a brand and the brand saboteur, our research focuses on other consumers who observe the CBS activity against a manufacturer brand. Therefore, we expand prior literature that has conceptually discussed but not empirically examined the potential damage caused by CBS (Kähr et al. 2016).

Second, we introduce the CBS phenomenon into a retailing context and examine whether the damage potential of CBS is so high that it could even negatively transfer to the retailer that was not involved in the brand transgression that stimulated CBS. Thus, to fully understand the negative consequences caused by CBS, we take a far-reaching network perspective that goes beyond the simple saboteur-manufacturer brand dyad. By doing so, we contribute to literature on retail branding that has examined the relationship between manufacturer brands and retailer brands. Rather than focusing on positive spillover effects from manufacturer brands to retailers, we examine the negative impact manufacturer brands may have on retailers in the context of CBS.

Third, previous research has not examined how retailers should respond to manufacturer-directed CBS. In our study, we provide insights into possible response strategies, that is, delisting versus continuing the sabotaged brand, in order to minimize negative spillover effects on consumers' attitude toward the retailer. Thereby, we take a differentiated approach by considering contingency factors that moderate the impact of these response strategies on consumer's attitude toward the retailer. More specifically, we examine whether the retailer should respond differently to CBS caused by performance failures or value conflicts and how this response should also vary depending on a retailer's characteristics such as its assortment size.

\section{RESEARCH FRAMEWORK}

Figure 1 presents the research framework that highlights the central constructs and hypotheses. Hypothesis 1 analyzes the negative spillover effect from the sabotaged manufacturer brand to the retailer. Once established, we examine the consequences of a retailer's assortment decision (continuing vs. delisting the sabotaged brand) on other consumers' attitude toward the retailer who had observed the CBS activity (hypothesis 2). Hypotheses 3 and 4 examine important characteristics of the sabotage activity (i.e., valuevs. performance-based CBS) and the retailer (i.e., its assortment size) that may moderate the impact of the retailer's assortment decision on its performance among consumers.

\section{Consumer Sabotage of a Manufacturer Brand and Spillover Effects to the Retailer}

The existing literature on consumer revenge and retaliation has shown that outraged consumers may do more than sim- 


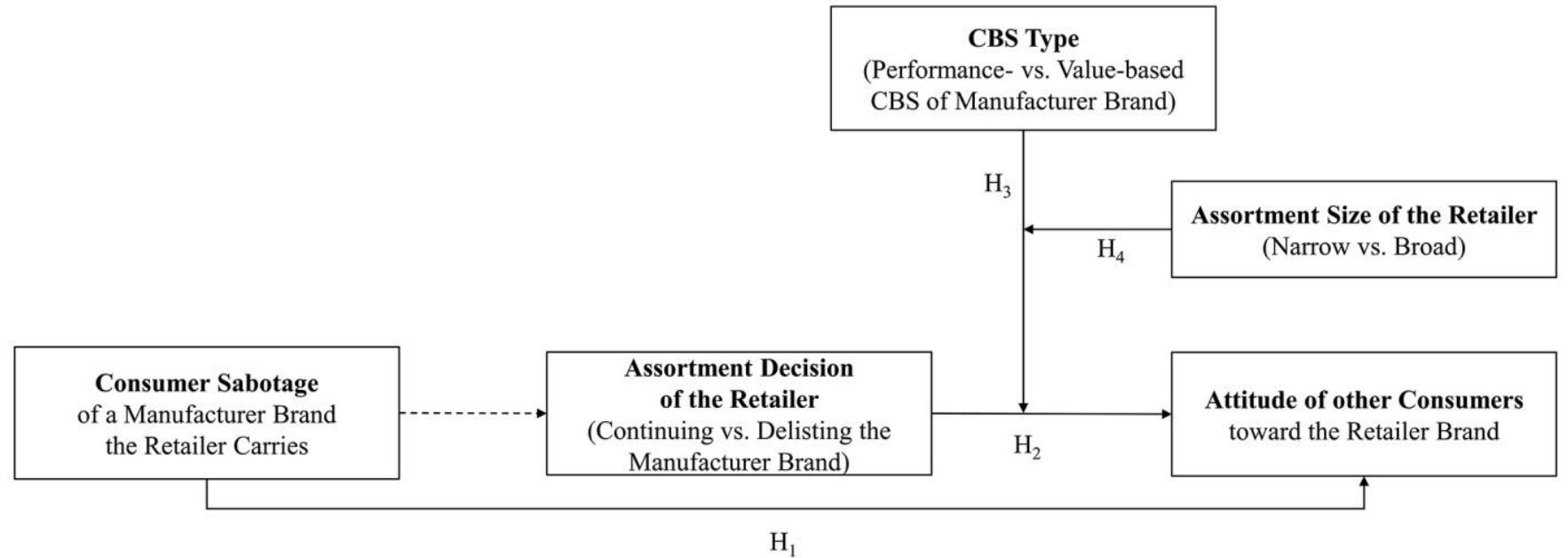

Figure 1. Research framework.

ply exit a relationship after negative brand experiences (e.g., Bechwati and Morrin 2003). In order to "get even" with a brand or company, consumers may try to punish brands by engaging in negative word of mouth or boycotting a brand (e.g., Grégoire and Fisher 2008; Grégoire et al. 2010). In case of CBS, consumers even go a step further by engaging in hostile aggression that involves the conscious desire to significantly harm the brand (Kähr et al. 2016). For that purpose, a brand saboteur tries to alter other consumers' attitude toward the brand in a negative way, which in a networked, digital world can be achieved relatively easily. By doing so, one single consumer can cause a brand to lose numerous existing customers and can alienate innumerable potential customers. Extending this previous research, we examine whether and how other brands that are not directly targeted by CBS activities but associated with the respective brand can get harmed (e.g., the retailer that sells the sabotaged brand).

Spillover effects have previously been studied in the context of brand alliances (e.g., Simonin and Ruth 1998; Rao, $\mathrm{Qu}$, and Ruekert 1999). In order to build and maintain strong brands, companies combine their brand with a successful brand of another company and make the resulting cooperation visible to consumers. As a consequence, the two cooperating brands become associated with one another in the minds of consumers (e.g., Keller 1993). Ideally, the positive associations of a partner brand are transferred to one's own brand. Brand alliances have also been studied in a retailing context, where retailers use brand alliances with manufacturer brands to enhance their image (Arnett, Laverie, and Wilcox 2010). The retailer-manufacturer brand coop- eration represents a special form of alliance, where the cooperating brands occupy different levels of the marketing channel (i.e., "cross-level" alliances; Jacoby and Mazursky 1984). Prior research in retailing has examined the positive impact of manufacturer brands on the evaluation of the retailer brand and its private labels (e.g., Simmons, Bickart, and Buchanan 2000) but rather ignored potential negative impacts.

In contrast, research on event-related spillover examined spillover effects of negative events, but the results have been somewhat mixed (i.e., finding negative, positive, and neutral spillover effects; e.g., Sullivan 1990; Votolato and Unnava 2006; Zhao, Zhao, and Helsen 2011) and appear to be highly dependent on context (e.g., Roehm and Brady 2007). Also, none of these studies has been conducted in a retailing context, which is different from the settings typically studied in the event-related spillover literature.

In sum, it is unclear what happens to a retailer when a crisis such as CBS occurs to a listed brand. To examine a possible negative spillover from a sabotaged brand to the retailer, we rely on the accessibility-diagnosticity framework of Feldman and Lynch (1988). This model has been applied in the context of brand alliances and spillover effects to predict the extent to which new information is used to form an evaluation and revise previous judgments (e.g., Roehm and Tybout 2006). Accessibility describes the ease with which a consumer can acquire a certain piece of information, either from memory or an external source (Hillyer and Tikoo 1995). In our context, a CBS activity should be highly accessible for consumers as it generally receives widespread (social) media attention. Diagnosticity refers to the extent to 
which inferences based on a piece of information alone are adequate to form an evaluation and attitude (Aaker and Maheswaran 1997). It has been argued that negative information is more diagnostic and therefore possibly more influential than positive information in the formation of overall evaluations (i.e., negativity bias; e.g., Ahluwalia, Burnkrant, and Unnava 2000; Roehm and Tybout 2006). Extremely negative information draws more attention and a greater level of cognitive elaboration on the information, which facilitates spillover onto related brands (Petty, Wegener, and Fabrigar 1997). Thus, manufacturer-directed CBS should be highly accessible and diagnostic for the evaluation of an affiliated brand (in our context, the retailer). Furthermore, since the previous literature has documented positive spillover from manufacturer to retailer brands, we would also expect a spillover effect in the case of negative information.

The consumer's brand attitude is a key indicator for how a consumer perceives a brand and strongly influences subsequent consumer behavior (Ajzen 2001), which makes it an important outcome variable in the context of spillover effects. Based on these considerations, we expect that consumers who learn of a sabotage act directed at a manufacturer brand will transfer this negative information also to the retailer that carries the respective brand, which in turn should influence consumer's attitude toward the retailer. This leads us to the following hypothesis:

H1: Consumers who have been exposed to a CBS activity against a manufacturer brand will have a more negative attitude toward the retailer that carries the brand.

\section{Retailer's Response to CBS of a Manufacturer Brand} Negative spillover effects should generally also depend on how a company responds to an underlying negative stimulus (e.g., Xie and Peng 2009). A key response decision for the retailer concerns whether to continue to carry the sabotaged brand or whether to drop it from its assortment.

In the context of brand alliances, it has been shown that a host brand can be affected not only by negative information about its partner brand but also by the consumers' belief that the host knew of and condoned the partner's behavior (Votolato and Unnava 2006). Thus, continuing to carry the brand after CBS has occurred may create the impression among consumers that the retailer tolerates the brand's misbehavior that has caused the sabotage activity. Further- more, consumers may also perceive this response strategy as a failure to take any action, which in turn can lead to a decrease in their attitude toward the retailer (e.g., Votolato and Unnava 2006; Xie and Peng 2009). Therefore, the retailer's decision to continue the relation with the sabotaged brand may negatively affect its performance among consumers.

An alternative response would be to delist the sabotaged brand. By doing so, the retailer distances itself from the brand that has fallen into disgrace. Consequently, consumers may not penalize the retailer because the link between the sabotaged brand (or its misbehavior) and the retailer has been removed (Votolato and Unnava 2006). Furthermore, by delisting the discredited brand, the retailer is seen as taking corrective action to prevent future problems with the manufacturer brand (Benoit 1997). Prior research has shown that taking corrective action is one of the most effective responses in repairing trust and bolstering attitude (e.g., Bradford and Garrett 1995; Dutta and Pullig 2011). We therefore postulate that compared to the continuation of the sabotaged brand, the delisting will decrease potential negative spillover effects and lead to a more positive attitude toward the retailer. This leads us to the following hypothesis:

H2: Delisting (vs. continuing) the sabotaged manufacturer brand leads to a more positive attitude toward the retailer.

Performance- versus Value-Based CBS. Our next hypothesis relates to the moderating effect of the type of CBS (Kähr et al. 2016). In the case of performance-based CBS, the brand saboteur acts in response to a brand's failure with regard to product and service quality (e.g., defective products, inaccurate bills) or interaction failures (e.g., excessive wait times, unfriendly responses on the customer hotline). When a consumer observes performance-based CBS, the attacked manufacturer brand is perceived as less competent as it is viewed as responsible for the underlying product and services failures. Value-based CBS, on the other hand, is evoked by brand stimuli, which relate to the brand's values (e.g., brand's communicated philosophy and brand identity) as well as any demonstration by the brand of unsocial or unethical behavior (e.g., a company uses sweat shop labor to enhance its profits).

Previous studies have argued that moral and competence information affect consumer responses in different ways 
(e.g., Skowronski and Carlston 1989; Brown and Dacin 1997). Specifically, consumers' impression formation is more strongly determined by the appraisal of morality and integrity than by the appraisal of competence (Wojciszke, Bazinska, and Jaworski 1998). Generally, information related to moral traits or behavior of a person is viewed as highly diagnostic in the appraisal of others. Every entity is expected to adhere to certain moral standards, therefore, a violation of values is associated with a conscious negative act by the brand and is less likely to be forgiven (Wojciszke, Brycz, and Borkenau 1993). In contrast, competence failures are viewed as less diagnostic. Such failures can always happen without intention, even among highly skilled individuals. Accordingly, consumers may be more willing to forgive performance failures associated with performance-based CBS. Furthermore, prior research has also shown that individuals who learn of a person's immoral behavior may experience a stronger emotional response than if this behavior would reveal that person's incompetence (Wojciszke et al. 1993).

In sum, consumers whose values are violated by the underlying transgression of the manufacturer brand perceive value-based $C B S$ as more severe and therefore more diagnostic than performance-based CBS. Because of this, they will more strongly expect the retailer to delist the brand when CBS is value-based. If the retailer does not delist a brand that has been sabotaged due to value issues, this may be perceived as consent to or even identification with the negative values. In the case of performance-based CBS, which is perceived as less severe, consumers will have a weaker expectation to delist the brand. As a consequence, the assortment decision of the retailer should have a stronger impact on consumers' brand attitude in the case of valuebased CBS. Thus, we hypothesize the following:

H3: The retailer's decision to delist (vs. continue) the manufacturer brand will have a more positive effect on the attitude toward the retailer in response to valuebased CBS among those consumers whose values are violated by the underlying transgression of the brand as compared to performance-based CBS.

Role of the Retailer's Brand Assortment. The differing impact of the type of CBS on the effectiveness of the retailer's assortment decision may also depend on retailer characteristics such as the assortment size, which is a key strategic decision for retailers (Kahn et al. 2014). In the current context, the size of a retailer's assortment determines the importance of a single manufacturer brand in the consumer's perception of the retailer. For a retailer with a narrow assortment, the manufacturer's brand image and retailer image are more strongly tied; therefore, a single manufacturer brand becomes highly diagnostic for consumers' overall evaluation and attitude toward the retailer (Feldman and Lynch 1988). Thus, spillover effects from a sabotaged brand to the retailer should be more likely to occur in case of a retailer offering a narrow assortment. For a retailer with a broad assortment, the retailer image is less likely to be determined by any one manufacturer's brand; therefore, this brand is less critical to the formation of overall evaluations. Thus, a retailer with a broad assortment should be less vulnerable to the sabotage of a single brand, and the delisting may hence have less impact on consumers' attitudes. We expect this effect to be particularly pronounced in case of valuebased CBS because this type of CBS should be perceived as more severe and more diagnostic than performance-based CBS.

Thus, overall, the stronger impact of a retailer's assortment decision on consumers' attitude toward the retailer in case of value-based CBS should be further reinforced for retailers with a narrow as compared to a broad assortment. In other words, the impact of the decision to delist a manufacturer brand that has been sabotaged based on value conflicts (compared to performance failures) will become even more critical for retailers with a narrow assortment. This leads us to the following hypothesis:

H4: The more positive effect of delisting (vs. continuing) a manufacturer brand in response to value-based CBS (compared to performance-based CBS) among those consumers whose values are violated by the underlying transgression of the brand is even stronger for retailers with a narrow (vs. broad) assortment.

\section{STUDY OVERVIEW}

In sum, we propose that a sabotaged manufacturer brand negatively affects the retailer that carries it (hypothesis 1 ). However, the retailer can decrease this negative effect by delisting the sabotaged brand (hypothesis 2). Furthermore, we expect that delisting the sabotaged brand is especially important when the sabotage occurred due to a value conflict as compared to a performance failure (hypothesis 3). Finally, we suggest that delisting the sabotaged brand due to a value conflict is more important for retailers with a narrow assortment (hypothesis 4). We test these propositions with two 
scenario-based experiments. The first experiment examines our hypotheses in the context of fictitious sports brands and the second with fictitious brands in the grocery market.

\section{STUDY 1}

\section{Method}

To test the proposed hypotheses, we conducted an online experiment on the crowdsourcing platform Clickworker. We applied a 2 (assortment decision of the retailer: continuing vs. delisting the sabotaged brand) $\times 2$ (type of sabotage: valuebased vs. performance-based CBS) $\times 2$ (assortment size of the retailer: narrow vs. broad) between-subjects design with fictitious brands from the sports market. We also included a control group who was only shown some general information about the retailer and the assortment size manipulation.

\section{Participants and Stimuli}

In study 1,539 consumers ( $51 \%$ female, $M_{\text {age }}=36$ ) participated. They first read three blocks of stimuli containing the manipulation of the retailer's assortment size, sabotage of the manufacturer brand, and the retailer's assortment decision. Each participant was randomly assigned to one of two conditions for each stimuli.

In a first block, we showed participants a general description about a fictitious sports' retailer. We then manipulated the retailer's assortment size by describing the choice of brands in general and within the product category of running shoes. Thereby, we also introduced Speedy Run, a fictitious manufacturer of running shoes, which the sports retailer carried according to our assortment description (see app. A; apps. A, $\mathrm{B}$ are available online). To the control group, only this general information about the retailer with the manipulation of the assortment size was shown (no manipulation of the type of CBS or assortment decision).

In the second block, after the manipulation of the retailer's assortment size, we showed participants a Facebook post of a consumer sabotaging the fictitious sports brand Speedy Run. In the value-based CBS scenario, the consumer was outraged about the exploiting working conditions of Speedy Run and pointed out that they employ child labor. In the performance-based CBS scenario, the consumer outlined Speedy Run's serious quality defects by describing how the sole of his expensive Speedy Run shoes detached from the shoe after barely using them. In both scenarios, the consumer urged other consumers to boycott Speedy Run and to read his blog wherein he describes the exploiting working conditions/the serious quality problems in more detail. To ensure that participants perceived the CBS scenarios as such and distin- guished between value- and performance-based sabotage, we conducted a pretest wherein we also tested the assortment size manipulation (see app. B).

In the third block, we presented the retailer's assortment decision to the sabotaged brand. Participants either read that the retailer decided to continue or delist the brand (see app. A).

\section{Measures}

Unless indicated otherwise, we used 7-point Likert scales ranging from 1 = "completely disagree" to $7=$ "completely agree" for all measures in this study. After having read the scenarios with the manipulations, the respondents had to report their attitude toward the retailer brand as dependent variable, which we measured with a five-item scale using a 7-point semantic differential adapted from Spears and Singh (2004). Subsequently, participants answered a series of control questions regarding the stimuli that served as manipulation checks. Specifically, we measured assortment size with a two-item scale adapted from Bauer, Kotouc, and Rudolph (2012), type of CBS with a two-item scale for each type adapted from Kähr et al. (2016), and assortment decision with three single-choice items (i.e., [1] continuing to carry, [2] delisting, and [3] I don't know). In addition, to measure whether participants perceived our scenarios as CBS, we used two items for the motive of harming the brand adapted from Kähr et al. (2016) and added two items based on their conceptualization of CBS. Furthermore, as the suggested effects of hypothesis 3 are contingent on a violation of the consumers' personal values (see study 3 in app. B for more details on this contingency), we assessed participants' perceived value conflict with the sabotaged brand's actions with a three-item scale adapted from Kähr et al. (2016). Finally, participants also reported demographic data (age and sex) before reading a debriefing (see table B1 for all items of the study and Cronbach's alpha; tables B1-B8 are available online in app. B).

\section{Results and Discussion}

Manipulation Checks. To test if the experimental factors varied as intended, we conducted three 2 (assortment decision) $\times 2$ (CBS type) $\times 2$ (assortment size) ANOVAs with the manipulation check measures for the CBS type and assortment size as dependent variables (see table B2). The first ANOVA revealed that participants who were confronted with the retailer that offered a broad assortment also reported significantly higher scores on the assortment size measure than participants in the narrow assortment condition (estimated marginal mean $[\mathrm{EMM}]=5.64, \mathrm{SE}=.09$ vs. $\mathrm{EMM}=2.62$, 
$\mathrm{SE}=.08 ; \quad F(1,431)=588.77, p<.001)$. The second ANOVA revealed that the performance-based CBS scenario was perceived as more strongly addressing the brand's performance compared to the value-based scenario (EMM $=6.20$, $\mathrm{SE}=.09$ vs. $\mathrm{EMM}=2.57, \mathrm{SE}=.10 ; F(1,431)=720.34$, $p<.001)$. Likewise, the third ANOVA showed that participants assessed the value-based CBS scenario as more strongly addressing values than the performance-based scenario $(\mathrm{EMM}=6.28, \mathrm{SE}=.11$ vs. $\mathrm{EMM}=3.91, \mathrm{SE}=.11$; $F(1,431)=229.61, p<.001)$. Furthermore, consumers in the value-based CBS condition reported that the actions of the sabotaged brand were in conflict with their personal values $(M=5.66, S E=.10)$. To ensure that participants perceived our CBS scenarios as sabotage, we examined whether they reached higher scores on the CBS scale than the midpoint of the scale, which was true for both scenarios $(M=5.93$, $\mathrm{SE}=.08$ and $M=5.40, \mathrm{SE}=.09$ ). Finally, to test whether participants understood whether the retailer continued to carry or delisted the sabotaged brand, we applied a fullfactorial binary logistic regression (see table B3). The continuation $(=0)$ versus delisting $(=1)$ condition served as significant predictor of the assessment of the assortment decision $(B=8.64, \mathrm{SE}=1.07 ; p<.001$; odds ratio $=5,622.62,95 \%$ confidence interval $[\mathrm{CI}]=[695.78,45,436.56] ; R^{2}=.87$ [Hosmer and Lemeshow], .70 [Cox and Snell], .93 [Nagelkerke]; model $\left.\chi^{2}(3)=518.18, p<.001\right)$.

Baseline Effect. We conducted a one-way independent ANOVA to examine whether the consumer sabotage of a manufacturer brand significantly decreased respondents' attitude toward the retailer brand compared to a control group without any sabotage. Participants in the CBS condition (averaged over the retailer's assortment decision) reported significantly lower scores in brand attitude than the control group $(M=3.76, \mathrm{SE}=.08$ vs. $M=4.97, \mathrm{SE}=.13 ; F(1,172)=$ 63.21, $p<.001$ ), supporting hypothesis 1 (see table B4). The result did not change whether or not we included participants' sex and age as control variables. For the subsequent analyses, the control group was excluded.

Moderating and Main Effects. To test our main effect of the assortment decision (continuation vs. delisting) on consumers' attitude toward the retailer and to examine how the type of CBS and the retailer's assortment size influence this main effect, we conducted a three-way independent ANOVA. The main effect of assortment decision on consumers' attitude toward the retailer was significant $(F(1,431)=36.91$, $p<.001$ ). Delisting (vs. continuing) the sabotaged brand led to significantly higher scores in consumers' attitude toward the retailer brand $(\mathrm{EMM}=4.20, \mathrm{SE}=.10$ vs. $\mathrm{EMM}=3.32$, $\mathrm{SE}=.11$ ), supporting hypothesis 2 . Furthermore, the twoway interaction between the assortment decision and type of CBS on consumers' attitude was significant $(F(1,431)=$ 6.12; $p<.05)$. Participants reported a higher attitude toward the retailer brand when the retailer delisted the sabotaged brand compared to its continuation for both the value-based CBS $(\mathrm{EMM}=4.52, \mathrm{SE}=.15$ vs. $\mathrm{EMM}=3.28$, $\mathrm{SE}=.16)$ and the performance-based $(\mathrm{EMM}=3.88, \mathrm{SE}=$ .14 vs. $\mathrm{EMM}=3.36, \mathrm{SE}=.14)$. In line with hypothesis 3 , the increase on consumers' brand attitude due to delisting the sabotaged brand was stronger for the value-based CBS than the performance-based CBS. Finally, the two-way interaction was qualified by a significant three-way interaction with assortment decision, type of CBS, and assortment size on consumers' attitude toward the retailer $(F(1,431)=3.93$, $p<.05$; see table B5). That is, the magnitude of the moderation by CBS type of the effect of the assortment decision on consumers' attitude toward the retailer brand depends on the retailer's assortment size. A simple slope analysis revealed that for value-based CBS, delisting the sabotaged brand significantly increased participants' attitude toward retailers with both a narrow assortment $(B=1.41, \mathrm{SE}=.27$; $t(431)=5.27, p<.001)$ and a broad assortment $(B=1.08$, $\mathrm{SE}=.31 ; t(431)=3.51, p<.001)$. In line with hypothesis 4 , for value-based CBS, the positive effect of the assortment decision on consumers' brand attitude was stronger for retailers with a narrow as compared to a broad assortment (however, this difference was not significant, $p=.42$; see fig. 2A). For performance-based CBS, we found the opposite effect with regard to assortment size. Delisting (vs. continuing) the sabotaged brand had a significant positive effect on consumers' brand attitude for retailers with a broad assortment $(B=.94, \mathrm{SE}=.30 ; t(431)=3.09, p<.01)$ but did not affect retailers with a narrow assortment $(B=.11, \mathrm{SE}=$ $.28 ; t(431)=.40, p=.69)$. Accordingly, for performancebased CBS, the positive effect of the assortment decision on consumers' attitude toward the retailer was significantly stronger for retailers with a broad assortment as compared to a narrow assortment $(B=.82 ; F(1,431)=3.98, p<.05$; see fig. $2 B$ ). The results did not change whether or not we included the control variables.

Discussion. The results of study 1 confirm a negative spillover effect of a sabotaged brand on the retailer. Consumers who have been confronted with manufacturer-directed CBS show a more negative attitude toward the retailer that 


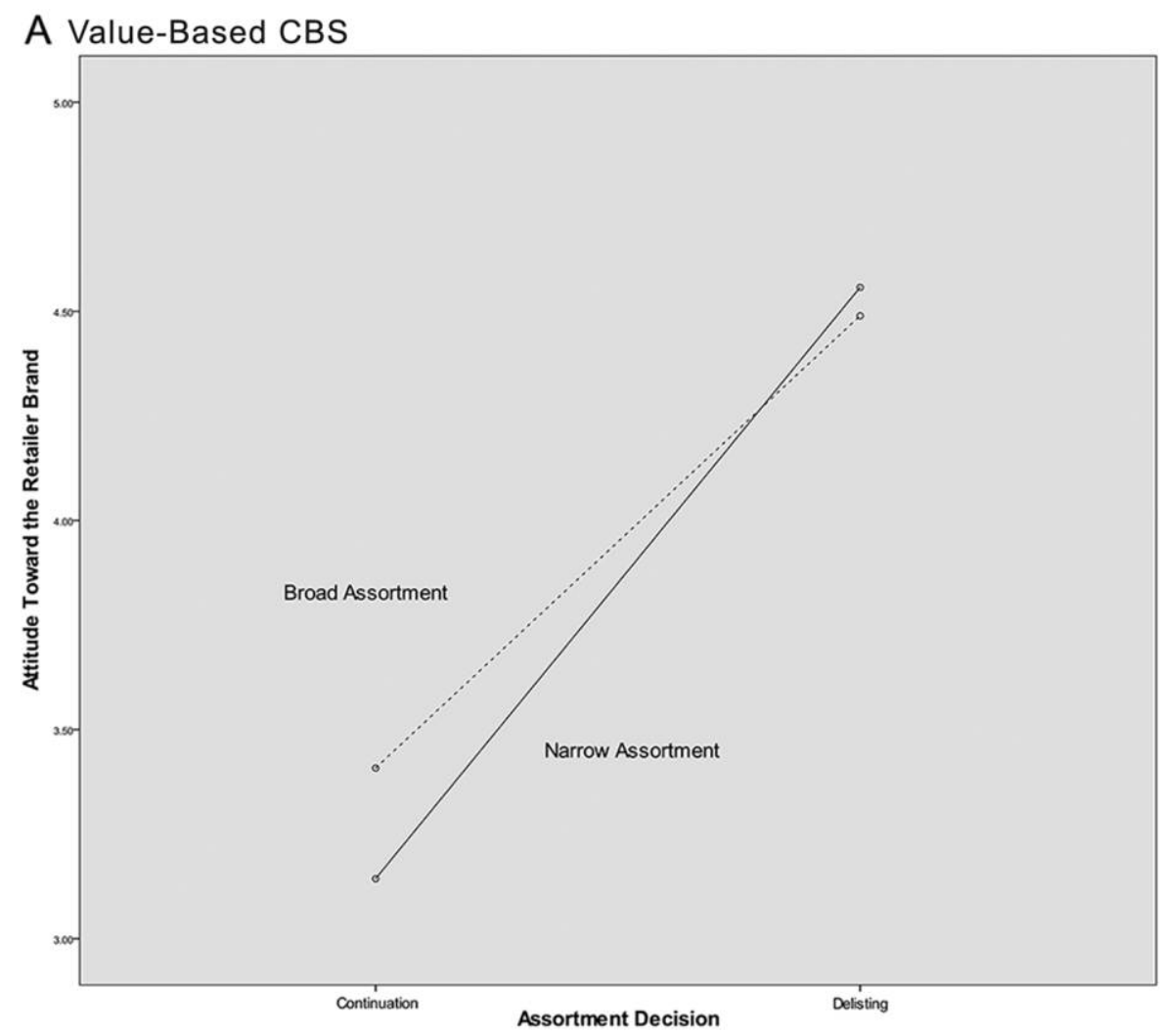

B Performance-Based CBS

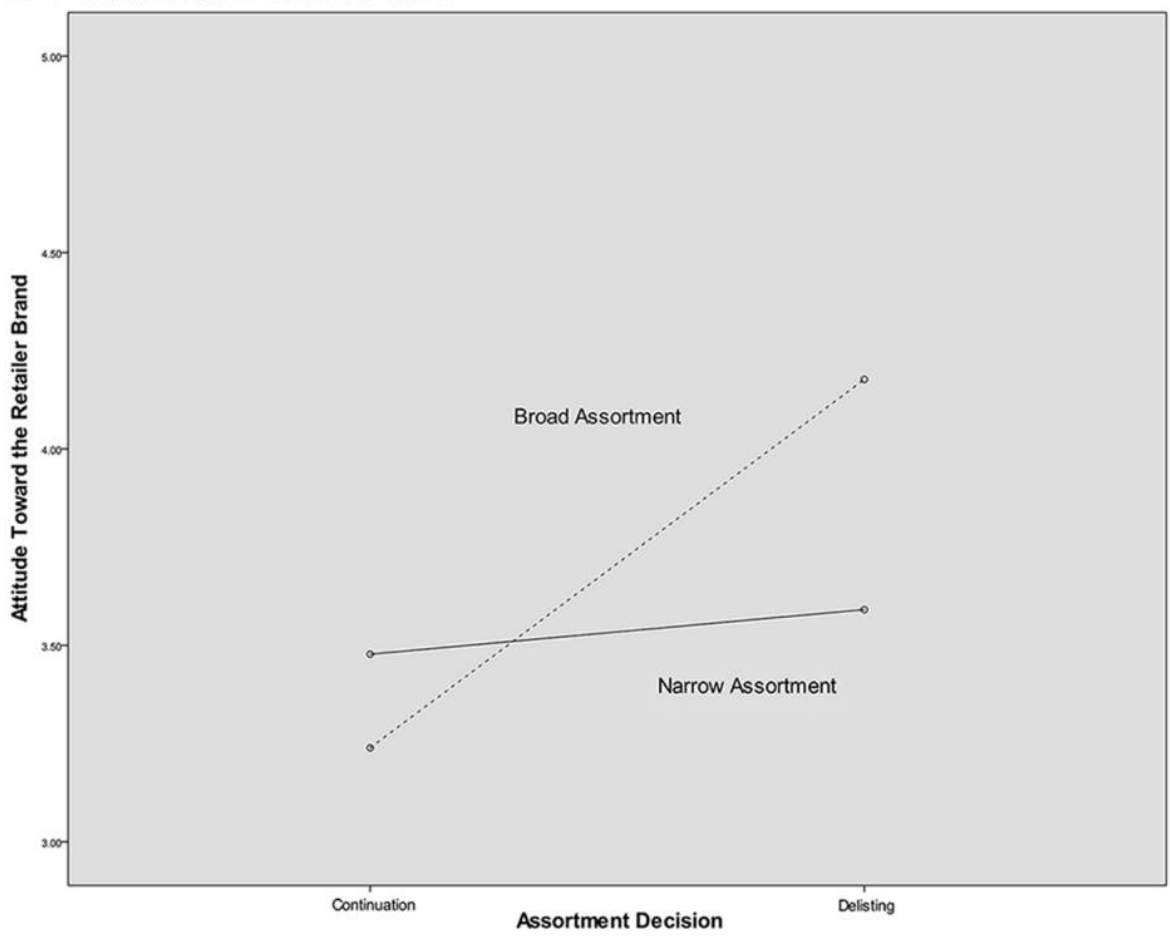

Figure 2. Study 1: Consumers' attitude toward the retailer brand after the retailer delisted (vs. continued to carry) the sabotaged manufacturer brand for retailers with a broad versus narrow assortment depending on the type of sabotage. A, Value-based CBS. Delisting (vs. continuing) the brand increases consumers' attitude for both retailers with a narrow and broad assortment but more strongly for retailers with a narrow assortment. B, Performance-based CBS. Delisting (vs. continuing) the brand only increases consumers' attitude for retailers with a broad assortment but not for retailers with a narrow assortment. 
carries the brand than consumers who have only been introduced to the manufacturer brand without any sabotage (supporting hypothesis 1 ). Our results also show that an appropriate reaction by the retailer can mitigate this negative effect. Delisting the sabotaged brand leads to a more positive attitude toward the retailer compared to continuing it (supporting hypothesis 2). Furthermore, the results show that this effect depends on the type of CBS. Delisting (vs. continuing) the sabotaged brand increased consumers' attitude toward the retailer more strongly in the case of value-based CBS compared to performance-based CBS (supporting hypothesis 3). In other words, delisting the sabotaged brand is more important for value-based as compared to performancebased CBS.

This effect also depends on the retailer's assortment size. As suggested in hypothesis 4 , we found a significant three-way interaction between assortment decision, type of CBS, and assortment size on consumers' attitude toward the retailer. In the case of value-based CBS, the positive effect of delisting a manufacturer brand on consumers' attitude was slightly more pronounced for a retailer with a narrow assortment. Interestingly, in the case of performance-based CBS, we found that the assortment decision of retailers with a narrow assortment did not significantly affect consumers' attitude toward the retailer. In contrast, for a retailer with a broad assortment, delisting (vs. continuing) the brand had a strong positive effect on consumers' attitude toward the retailer.

One explanation for this unexpected finding could be that in addition to our diagnosticity-accessibility considerations, other cognitive processes may also play a role. More specifically, we suggest that consumers' fairness perceptions may mediate the relationship between the retailer's assortment decision and consumers' attitude toward the retailer (which is moderated by the type of CBS and assortment size). Fairness considerations are highly relevant when consumers evaluate a company's marketing activities and the corresponding interactions, with a higher fairness perception leading to a more positive attitude toward the company (e.g., Aggarwal 2004). Perceived fairness is defined as the extent to which sacrifice and benefit are commensurate for each partner involved (Bolton, Warlop, and Alba 2003). This mutual consideration of individual benefits and sacrifices is based on equity theory, which takes the outcomes for both transaction partners into account, that is, for the company and the consumer, rather than the outcome for the consumer alone (e.g., Xia, Monroe, and Cox 2004). Transferred to our context, consumers should evaluate a retailer's decision to delist (vs. continue) a sabotaged manufacturer brand based on fairness considerations, taking into account the resulting benefits and sacrifices of the retailer.

We argue that a retailer with a broad assortment is less dependent on a single manufacturer brand as the retailer has a large number of alternative brands in its assortment. Therefore, after delisting a sabotaged brand, the retailer's remaining assortment is still attractive to consumers, thereby, leading to stable future revenues (with regard to the effects of assortment size on consumer preferences, see also Kahn and Lehmann [1991]). On the other hand, a retailer with a more specialized and narrow assortment is more vulnerable to delisting a brand as it faces the risk of becoming less attractive to consumers which can significantly lower sales (Ailawadi and Keller 2004). Accordingly, consumers may perceive the delisting of a manufacturer brand as greater sacrifice for retailers with a narrow assortment than for retailers with a broad assortment, influencing their fairness perceptions.

Further, these fairness considerations regarding the retailer's delisting (vs. continuing) a sabotaged brand may differ for value- versus performance-based CBS. In the case of valuebased CBS, consumers may evaluate the violation of values by the manufacturer brand as conscious negative act which is less likely to be forgiven (Wojciszke et al. 1993). Consequently, consumers may hold high expectations that the retailer will delist the sabotaged brand, in order to distance itself from the immoral behavior. Thus, from the consumers' perspective, the only fair retailer response is to delist the sabotaged brand, especially for a retailer with a narrow assortment, where the single manufacturer brand is highly important for consumers' evaluation of the retailer (Feldman and Lynch 1988). Thus, we propose that in the case of value-based CBS, the retailer's decision to delist (vs. continue) the sabotaged brand increases consumers' perceived fairness of the decision more strongly for retailers with a narrow assortment compared to a broad assortment, which in turn increases consumers' attitude toward the retailer.

In the case of performance-based CBS, on the other hand, the underlying performance failure may be perceived as less severe, easier to repair, and hence less diagnostic than the violation of values with value-based CBS (see also Wojciszke et al. 1998). Here consumers are more forgiving (as the brand may perform well again in the future), and consumers' expectations and perceived benefits of delisting the brand may be lower. Thus, considering the high sacrifice for retailers with a narrow assortment, consumers may recognize that especially for a small retailer, the costs of dropping a sabotaged brand outweigh the potential benefits for the consumers. Accordingly, they may perceive the delisting of a brand that was 
sabotaged based on performance failures as less fair for a retailer with a narrow assortment. For a retailer with a broad assortment, on the other hand, the perceived sacrifice of delisting the sabotaged brand is smaller, and consumers perceive it as fair to delist the brand in order to offer only highquality products without any performance failures, leading to a more positive attitude toward the retailer. Thus, we propose that in the case of performance-based CBS, the retailer's decision to delist (vs. continue) the sabotaged manufacturer brand increases consumers' perceived fairness of the decision more strongly for retailers with a broad assortment compared to a narrow assortment, which in turn increases consumers' attitude toward the retailer.

\section{STUDY 2}

Study 2 was designed to replicate the results of study 1 and to examine the process by which the assortment decision affects consumers' attitude toward the retailer, depending on the CBS type and assortment size. To do so, consumers' perceived fairness of the assortment decision was measured as possible mediating variable.

\section{Method}

We conducted an online experiment on the platform Clickworker with the same three factorial between-subjects design as in study 1 but with fictitious brands in the grocery market. More specifically, we used a 2 (assortment decision of retailer: continuing vs. delisting) $\times 2$ (type of sabotage: value-based vs. performance-based) $\times 2$ (assortment size: narrow vs. broad) factorial between-subjects design with a control group who was only shown some general information about the retailer and the assortment size manipulation.

\section{Participants and Stimuli}

Five hundred and seven participants (50\% male, $M_{\text {age }}=34$ ) took part in our study. The structure of the experiment followed the same logic as in study 1 . Participants read three blocks of stimuli containing the manipulations of the retailer's assortment size, sabotage of the manufacturer brand, and the retailer's assortment decision. Participants were again randomly assigned to one of the two conditions for each stimuli. In the first block, we manipulated the retailer's assortment size by first providing some general information about the retailer and then describing the choice of brands in general and within the product category of chocolate bars. Thereby, we introduced Zeidel, a fictitious manufacturer of chocolate products that the retailer carries according to our assort- ment description (see app. A). To the control group, only this first of three blocks was shown (i.e., general description of the retailer and assortment size manipulation).

In the second block, participants read a Facebook post of a consumer sabotaging Zeidel. In both, the value- and performance-based CBS, the consumer shared a blog post wherein he further describes the performance- or valuerelated issues of Zeidel. In the value-based CBS, the consumer was outraged that Zeidel was using palm oil to produce its chocolate bars since that can lead to deforestation. In the performance-based CBS, the consumer broke a tooth because of a piece of plastic in a Zeidel's chocolate bar. In both scenarios, the consumer encourages others to read his blog about Zeidel's misconduct and to boycott the brand (see app. A).

In the third section, we manipulated the retailer's reaction. We used the same manipulation as in study 1 and replaced the names of the retailer and the manufacturer with those of study 2 (see app. A). To ensure that our scenarios were perceived as intended, we conducted a pretest (see app. B).

\section{Measures}

Following the scenarios, participants had to report their perceived fairness of the retailer's assortment decision with a two-item scale ( 1 = completely disagree to $7=$ completely agree) adapted from Bolton, Keh, and Alba (2010), followed by their attitude toward the retailer, manipulation checks, and demographics which were the same as in study 1 . At the end of the study, participants received a debriefing (see table B1 for all items of the study and Cronbach's alpha).

\section{Results and Discussion}

Manipulation Check. We conducted three 2 (assortment decision) $\times 2$ (CBS type) $\times 2$ (assortment size) ANOVAs with the manipulation check measures for the type of CBS and assortment size as dependent variables to test if the experimental factors varied as intended (see table B2). The first ANOVA showed that the score on the assortment size measure was significantly higher for participants in the broad assortment condition than in the narrow assortment condition $(\mathrm{EMM}=6.05, \mathrm{SE}=.09$ vs. $\mathrm{EMM}=2.55, \mathrm{SE}=.09$; $F(1,378)=798.41, p<.001)$. The second ANOVA revealed that the performance-based CBS scenario was more strongly perceived as addressing the brand's performance compared to the value-based scenario $(\mathrm{EMM}=5.57, \mathrm{SE}=.10 \mathrm{vs}$. $\mathrm{EMM}=3.39, \mathrm{SE}=.10 ; F(1,378)=219.04, p<.001)$. The third ANOVA showed that participants assessed the value-based CBS scenario as more strongly addressing val- 
ues than the performance-based scenario $(E M M=5.71$, $\mathrm{SE}=.11$ vs. $\mathrm{EMM}=4.71, \mathrm{SE}=.11 ; F(1,378)=39.27$, $p<.001)$. Also, participants in the value-based CBS scenario reported that the sabotaged brand's actions were in conflict with their personal values $(M=5.33, \mathrm{SE}=.10)$. Again, the performance-based and value-based CBS scenarios were both perceived as CBS (i.e., $M>4.0$ on the CBS scale: $M=$ 5.28, $\mathrm{SE}=.09$ and $M=5.42, \mathrm{SE}=.10)$.

Finally, to examine whether participants understood whether the retailer continued or delisted the sabotaged brand, we again applied a full-factorial binary logistic regression (see table B3). This regression analysis revealed that the continuation versus delisting condition served as significant predictor for the assortment decision measure $(B=9.38, \mathrm{SE}=$ $1.16 ; p<.001$; odds ratio $=11,814.43,95 \%$ CI $[1,217.79$, 114,618.55]; $R^{2}=.92$ [Hosmer and Lemeshow], .72 [Cox and Snell], .96 [Nagelkerke]; model $\chi^{2}(3)=484.99, p<$ .001).

Baseline Effects. We conducted a one-way independent ANOVA to test whether the sabotage scenarios significantly decreased other consumers' perception of the retailer compared to the control group. Participants in the CBS condition (averaged over the retailer's assortment decision) reported significantly lower scores in brand attitude than the control group $(M=4.30, \mathrm{SE}=.07$ vs. $M=5.41, \mathrm{SE}=.10$; $F(1,191)=81.08, p<.001$ ), supporting hypothesis 1 (see table B4). The results did not change whether or not we included the control variables. For the subsequent analyses, the control group was excluded.

Moderating and Main Effects. We ran a three-way independent ANOVA to test our main effect of the assortment decision (continuation vs. delisting) on consumers' attitude toward the retailer and to probe how this effect depends on the type of CBS and the retailer's assortment size. The results again revealed a significant main effect of the assortment decision on consumers' attitude $(F(1,378)=32.76, p<.001)$. Supporting hypothesis 2 , delisting the sabotaged brand led to more positive attitudes toward the retailer than its continuation $(\mathrm{EMM}=4.73, \mathrm{SE}=.10$ vs. $\mathrm{EMM}=3.94, \mathrm{SE}=$ .10). Furthermore, the two-way interaction with assortment decision and CBS type on brand attitude was significant $(F(1,378)=14.00, p<.001)$. Delisting the sabotaged brand again led to significantly higher attitudes toward the retailer than its continuation for both the value-based CBS $(\mathrm{EMM}=5.03, \mathrm{SE}=.14$ vs. $\mathrm{EMM}=3.71, \mathrm{SE}=.14)$ and the performance-based $(\mathrm{EMM}=4.43, \mathrm{SE}=.14 \mathrm{vs}$. $\mathrm{EMM}=$
$4.16, \mathrm{SE}=.14)$. In line with hypothesis 3 , the increase on consumers' brand attitude due to delisting the sabotaged brand was much stronger for value-based compared to performance-based CBS. Again, these results were qualified by a significant three-way interaction with assortment decision, type of CBS, and assortment size on consumers' attitude toward the retailer brand $(F(1,378)=6.89, p<.01$; see table B5). A simple slope analysis showed that, in case of value-based CBS, delisting versus continuing the sabotaged brand significantly increased consumers' attitude for both retailers with a narrow assortment $(B=1.63$, SE $=.26$; $t(378)=6.28, p<.001)$ and broad assortment $(B=1.00$, $\mathrm{SE}=.27 ; t(378)=3.70, p<.001)$. Therefore, for valuebased CBS, the positive effect of the assortment decision on consumers' brand attitude was stronger for a narrow assortment than a broad assortment (although this difference was only marginally significant, $B=-.63 ; F(1,378)=2.83$, $p=.09$; see fig. $3 A$ ). In contrast, in the case of performancebased CBS, delisting only led to a more positive brand attiude for retailers with a broad assortment $(B=.69, \mathrm{SE}=$ $.29 ; t(378)=2.36, p<.05)$ but not for those with a narrow assortment $(B=-.14, \mathrm{SE}=.30 ; t(378)=-.47, p=.64)$. Thus, in case of performance-based CBS, the positive effect of the assortment decision on consumers' attitude was significantly stronger for retailers with a broad assortment than a narrow assortment $(B=.83 ; F(1,378)=3.98, p<.05$; see fig. $3 B$ ). The results did not change whether or not we included the control variables.

Conditional Moderated Mediation Effects. To analyze the process by which the three-way interaction of the retailer's assortment decision with the type of CBS and the assortment size affects consumers' attitude toward the retailer, we conducted a conditional process analysis using ordinary least squares path analysis with PROCESS model 11 (bootstrapping of 10,000 samples; Hayes 2013, 2015). Assortment decision served as independent variable ( $0=$ continuation, 1 = delisting), CBS type as first-stage moderator $(0=$ performance-based, $1=$ value-based CBS $)$ interacting with assortment size as second moderator ( $0=$ narrow assortment, 1 = broad assortment), consumers' fairness perception of the assortment decision as mediator, and their attitude toward the retailer brand as dependent variable. The $95 \% \mathrm{CI}$ of the index of moderated mediation excluded zero $\left(a_{7} b=-.60, \mathrm{SE}=.28 ; 95 \% \mathrm{CI}=[-1.1618\right.$, $-.0795])$, indicating that the consumers' perceived fairness mediates the three-way interaction of assortment decision, CBS type, and assortment size on brand attitude (see 

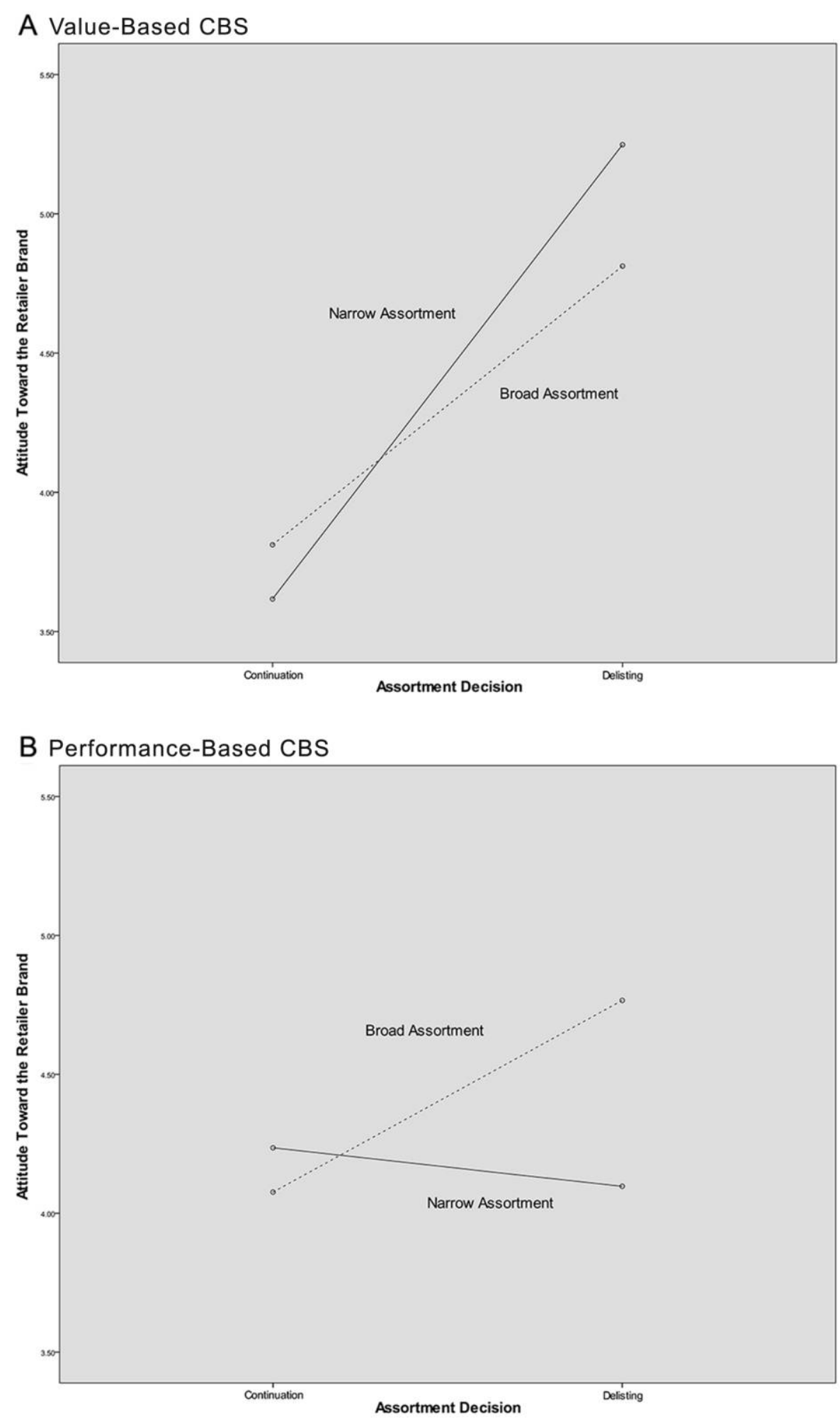

Figure 3. Study 2: Consumers' attitude toward the retailer brand after the retailer delisted (vs. continued to carry) the sabotaged manufacturer brand for retailers with a broad versus narrow assortment depending on the type of sabotage. A, Value-based CBS. Delisting (vs. continuing) the brand increases consumers' attitude for both retailers with a narrow and broad assortment but more strongly for retailers with a narrow assortment. $B$, Performance-based CBS. Delisting (vs. continuing) the brand only increases consumers' attitude for retailers with a broad assortment but not for retailers with a narrow assortment. 
table B6). Considering the moderated path from the assortment decision to fairness perception, the analysis revealed that the main effect of assortment decision was nonsignificant $\left(c^{\prime}=.14, \mathrm{SE}=.14 ; p=.31\right)$. The two-way interaction between assortment decision and CBS type on consumers' perceived fairness was significant $\left(a_{4}=2.98, \mathrm{SE}=.44\right.$; $p<.001)$. This interaction was qualified by a significant three-way interaction between assortment decision, CBS type, and assortment size on participants' fairness perception $\left(a_{7}=-1.39, \mathrm{SE}=.63 ; p<.05\right)$. For value-based $\mathrm{CBS}$, a significant conditional indirect effect of delisting versus continuing the sabotaged brand on consumers' brand attitude was found for both retailers with a narrow assortment $(B=1.32, \mathrm{SE}=.18 ; 95 \%$ CI $[.9891,1.6818])$ and a broad assortment $(B=.99, \mathrm{SE}=.18 ; 95 \%$ CI [.6440, 1.3637]). In line with our proposition, this conditional indirect effect of the assortment decision on consumers' brand attitude was stronger for retailers with a narrow compared to a broad assortment. In contrast, for performance-based CBS, delisting versus continuing the sabotaged brand only had a significant conditional indirect effect on consumers' brand attitude for retailers with a broad assortment $(B=.30, \mathrm{SE}=.14 ; 95 \%$ CI $[.0333, .5727])$ but not for retailers with a narrow assortment $(B=.02, \mathrm{SE}=.15$; $95 \%$ CI $[-.2638, .3067])$, supporting our proposition. Thus, consumers evaluate the retailers' decision to delist a brand that was sabotaged due to a value conflict as more fair than its continuation, especially for retailers with a narrow assortment, which increases their attitude toward the retailer brand. On the other hand, in case of performance-based CBS, delisting versus continuing the sabotaged brand is perceived as more fair, increasing consumers' attitude toward the retailer brand, only for retailers with a broad assortment. For retailers with a narrow assortment, their assortment decision does not increase consumers' attitude toward the retailer brand via their fairness perception. The results did not change whether or not we included the control variables.

Discussion. Study 2 was able to replicate the results of study 1 . We again showed that there is a negative spillover effect from the sabotaged brand to the retailer and that the retailer can mitigate this negative effect by delisting the brand. Such a delisting of the sabotaged brand is even more important for value-based compared to performance-based CBS. For those retailers confronted with value-based CBS, it is crucial to delist the sabotaged brand (even more so for retailers with a narrow assortment). In contrast, delisting a brand that was sabotaged due to a performance failure only increased consumers' attitude for a retailer with a broad assortment but not for a narrow assortment. Finally, to better understand this three-way interaction with assortment decision, CBS type, and assortment size, we included consumers' perceived fairness of the assortment decision as mediator of the effect of the retailer's assortment decision on consumers' attitude toward the retailer. The results showed that consumers perceived it as fair to delist a sabotaged brand due to a value conflict which increased their attitude toward the retailer brand, both for retailers with a broad and a narrow assortment and slightly stronger for retailers with a narrow assortment. In contrast, delisting a sabotaged brand due to a performance failure was perceived as fair only for retailers with a broad assortment, increasing their brand attitude. For retailers with a narrow assortment, consumers' perceived it as equally fair whether the retailer delisted or continued the sabotaged brand. Overall, these results suggest that fairness perceptions may explain why the retailer's assortment decision does not always affect consumers' attitude toward the retailer in the same way, depending on the assortment size.

\section{GENERAL DISCUSSION}

Due to the fast changing retailing landscape where consumers are empowered by digital technologies, consumers can now with relatively little effort become brand saboteurs and severely damage other consumers' attitudes toward manufacturers' and retailers' brands. This phenomenon of CBS is especially challenging for retailers as not only their own brand but also the manufacturer brands they carry can become victims of $C B S$.

Our findings from two experiments indicate that CBS toward a manufacturer brand significantly influences other consumers' perception of the retailer that carries the sabotaged brand. Specifically, manufacturer-directed CBS has a significant negative spillover effect on other consumers' attitude toward the retailer. However, our results also illustrate that an appropriate reaction by the retailer can mitigate this negative effect. In all studies, we found that delisting the sabotaged brand (as compared to continuing it) strengthens consumers' attitude toward the retailer.

Furthermore, our results show that the retailer's assortment decision in response to CBS of a manufacturer brand has different effects in the case of performance-based CBS (sabotage stimulated by performance failure) versus valuebased CBS (sabotage stimulated by value conflicts). As expected, in both studies we found that the retailer's assortment decision had a stronger impact on consumers' attitude 
in the case of value-based CBS, and delisting the sabotaged brand increased consumers' attitude toward the retailer more strongly for the value-based as compared to the performancebased CBS.

Our results further show that the moderating effect of the type of CBS depends on the retailer's characteristics, namely, its assortment size. We found some initial evidence that the impact of the decision to delist a brand that has been sabotaged based on value conflicts is even more critical for retailers with a narrow assortment. In other words, especially for retailers with a narrow assortment, delisting the brand should increase consumers' attitude toward the retailer more strongly when the sabotage occurred due to a value conflict (value-based CBS) than when it was based on a performance failure (performance-based CBS). Interestingly, in the case of performance-based CBS, we found that delisting the sabotaged brand increased consumers' attitude toward retailers with a broad assortment but not for retailers with a narrow assortment. In order to better understand the cognitive processes that drive these interactions, we examined consumers' perceived fairness of the retailer's response as an important mediator. In this regard, we found that in case of value-based CBS, delisting the brand was perceived as a fair choice for retailers with both narrow and broad assortments (although slightly stronger for retailers with a narrow assortment), driving consumers' attitudes toward the retailer. In case of performance-based CBS, delisting the sabotaged brand was perceived as fair for retailers with a broad assortment. In contrast, consumers did not expect a retailer with a narrow assortment to delist the sabotaged brand, as it did not increase consumers' fairness perceptions and corresponding attitude. Therefore, fairness perceptions may help to explain why delisting (vs. continuing) a sabotaged brand does not always affect consumers' attitude toward the retailer brand in the same way (as they vary depending on the type of CBS and the retailer's assortment size).

\section{Academic Implications}

Our study makes several important contributions to the literature. First, while prior research has conceptually discussed the potential damage caused by CBS (Kähr et al. 2016), we are the first study to provide empirical insights on the damage of CBS. Our empirical studies show that the negative effect of CBS is substantial. Not only can these activities harm the sabotaged brand but there is also a significant impact on the retailer that carries the brand. Given the importance of this phenomenon, it is critical to develop a bet- ter understanding of when these negative effects occur and how retailers should respond to it. Our study underlines the importance of assortment size, the type of CBS, and customers' perceived fairness in this regard.

We further contribute to literature on brand transgressions by taking a different approach from previous studies and examining possible downstream, indirect effects of brand transgressions (e.g., Smith and Bolton 1998; Tax, Brown, and Chandrashekaran 1998; Aaker, Fournier, and Brasel 2004). Rather than studying the dyadic relationship between an individual consumer and the brand committing the transgression, we examine the impact of the consumer's response to the transgression and how this affects other consumers who observe this response. We therefore recognize that brand transgressions can cause a complex chain of negative effects on related brands.

Second, we contribute to literature on retail branding that has already examined the relationship between manufacturer brands and retailer brands. However, rather than focusing on positive spillover effects from manufacturer brands to retailers as in prior research (e.g., Jacoby and Mazursky 1984), we find evidence for negative spillover effects from manufacturer brands to retailer brands, fueled by manufacturerdirected brand sabotage. This also contributes to the literature on alliance-related spillover effects, which has also focused on positive spillover effects (e.g., Simonin and Ruth 1998; Lou, Tsai, and Yan 2008). We further demonstrate that these negative spillover effects can occur for a different type of alliance than is normally studied (i.e., cross-level alliances). Thus, even in instances where the brand's alliances are at different levels and ties are not as strong, there can be substantial negative spillovers in response to CBS activities.

In addition, as mentioned previously, the findings of research on event-related spillover have been mixed and highly context-dependent (e.g., Votolato and Unnava 2006; Roehm and Brady 2007; Zhao et al. 2011). We add to our knowledge in this area by documenting negative spillover effects in a very specific and important context: the retailer-manufacturer relationship. In addition, we identified important moderators (i.e., assortment size and type of CBS activity) and a mediator (perceived fairness of the retailer's response) that contribute to our knowledge of when and how these negative spillover effects occur.

Third, we provide insights on how retailers should respond to CBS of a manufacturer brand in order to minimize negative effects on consumers' attitudes toward the retailer. Therefore, we take a differentiated approach by considering contingency factors that moderate the impact of these re- 
sponse strategies on consumer's attitude toward the retailer. More specifically, we examine whether the retailer should respond differently to CBS caused by performance failures or value conflicts and how this response should also vary depending on a retailer's characteristics such as its assortment size. With these insights, we contribute to research on alliance- and event-related spillover effects which has identified antecedents and moderators influencing the degree of spillover (e.g., Roehm and Brady 2007; Zhang and Taylor 2009). However, these studies have not been conducted in a retailing context and have neglected cross-company response strategies to reduce negative spillover. Our study contributes to fill this research gap as we show how a partner in an alliance (the retailer) should respond to negative events that occurred to the other partner (sabotaged manufacturer brand) in order to reduce negative spillover effects.

\section{Managerial Implications}

Our study also provides important insights for managers. First, retail managers need to realize that their own brand is vulnerable to CBS even if the target is just one of the brands they carry. Thus, retail managers need to carefully monitor not only their own brand but also all the manufacturer brands they carry in order to detect acts of brand sabotage toward these brands early (e.g., in social media) before it affects their revenues and especially their brand image. This would enable them to proactively develop an appropriate response strategy. Furthermore, retail managers should recognize that in some cases swift and radical actions may be required-sometimes even delisting the sabotaged brand. Therefore, our study shows that retailers need to consider the type of CBS and the assortment size in formulating the correct response. For example, our results show that delisting is highly important for retailers with a narrow assortment as a response to value-based CBS in driving consumers' attitudes toward the retailer. On the other hand, there is no urgency for a retailer with a narrow assortment to delist a brand that was sabotaged based on performance failures. While in such assortment decisions managers sometimes focus on the trade-off between ethical aspects and profitability, our study provides managers with the key insight that, in the context of retailing and CBS, ethics (value conflicts and the retailer's response to it) do drive brand performance (consumers' brand attitudes).

\section{Future Research}

A main avenue for future studies would be to examine other potential moderators that influence the outcomes of the re- tailer's response to the sabotaged brand. For example, characteristics of the retailer such as the retailer's brand image (Ailawadi and Keller 2004) may play an important role. On the one hand, the decision to delist the manufacturer brand could be more important for retailers with a strong brand image, as the image stored in the long-term memory of consumers strongly influences the expectations consumers have with regard to the behavior of this brand (e.g., Smith and Swinyard 1982). On the other hand, the possibility exists that retailers with a strong brand image are more immune to CBS that occurs to one of its carried brands because consumers have strong positive attitudes toward this retailer. This would suggest that retailers with a weak image are more vulnerable to CBS activities. Future research is needed to investigate these interesting possibilities.

Furthermore, we found that delisting a sabotaged brand may lead to more positive attitudes toward the retailer. However, such a strategy may not always be viable or reasonable. In other words, it is more difficult for retailers to delist highselling brands that contribute significantly to the retailer's profits or when there is a strong relationship between the retailer and the manufacturer. Thus, further research could examine under what conditions a retailer could continue the sabotaged brand. One important factor could be the retailer's communication. For example, by providing an explanation for a negative event, consumers' trust can be restored (e.g., Dutta and Pullig 2011). In our context, the retailer could communicate why it wants to continue the sabotaged brand. Also, other manufacturer characteristics such as the strength of the manufacturer's brand or even the congruence between the manufacturer and the retailer brand may also play a key role in responding to $\mathrm{CBS}$ activities that could be examined by future research.

\section{REFERENCES}

Aaker, Jennifer, Susan Fournier, and S. Adam Brasel (2004), "When Good Brands Do Bad," Journal of Consumer Research, 31 (1), 1-16.

Aaker, Jennifer, and Durairaj Maheswaran (1997), "The Effect of Cultural Orientation on Persuasion," Journal of Consumer Research, 24 (3), 315-28.

Aggarwal, Pankaj (2004), "The Effects of Brand Relationship Norms on Consumer Attitudes and Behavior," Journal of Consumer Research, 31 (1), 87-101.

Ahluwalia, Rohini, Robert E. Burnkrant, and H. Rao Unnava (2000), “Consumer Response to Negative Publicity: The Moderating Role of Commitment,” Journal of Marketing Research, 37 (2), 203-14.

Ailawadi, Kusum L., and Kevin Lane Keller (2004), "Understanding Retail Branding: Conceptual Insights and Research Priorities," Journal of Retailing, 80 (4), 331-42.

Ajzen, Icek (2001), "Nature and Operation of Attitudes," Annual Review of Psychologv, 52 (February), 27-58. 
Arnett, Dennis B., Debra A. Laverie, and James B. Wilcox (2010), “A Longitudinal Examination of the Effects of Retailer-Manufacturer Brand Alliances: The Role of Perceived Fit," Journal of Marketing Management, 26 (1-2), 5-27.

Bauer, Johannes C., Alexander J. Kotouc, and Thomas Rudolph (2012), "What Constitutes a 'Good Assortment'? A Scale for Measuring Consumers' Perceptions of an Assortment Offered in a Grocery Category," Journal of Retailing and Consumer Services, 19 (1), 11-26.

Bechwati, Nada Nasr, and Maureen Morrin (2003), "Outraged Consumers: Getting Even at the Expense of Getting a Good Deal," Journal of Consumer Psychology, 13 (4), 440-53.

Benoit, William L. (1997), "Image Repair Discourse and Crisis Communication," Public Relations Review, 23 (2), 177-86.

Bolton, Lisa E., Hean Tat Keh, and Joseph W. Alba (2010), "How Do Price Fairness Perceptions Differ across Culture?” Journal of Marketing Research, 47 (3), 564-76

Bolton, Lisa E., Luk Warlop, and Joseph W. Alba (2003), “Consumer Perceptions of Price (Un)Fairness," Journal of Consumer Research, 29 (4), 474-91.

Bradford, Jeffrey L., and Dennis E. Garrett (1995), "The Effectiveness of Corporate Communicative Responses to Accusations of Unethical Behavior," Journal of Business Ethics, 14 (11), 875-92.

Brown, Tom J., and Peter A. Dacin (1997), "The Company and The Product: Corporate Associations and Consumer Product Responses," Journal of Marketing, 61 (1), 68-84.

Dutta, Sujay, and Chris Pullig (2011), "Effectiveness of Corporate Responses to Brand Crises: The Role of Crisis Type and Response Strategies," Journal of Business Research, 64 (12), 1281-87.

Feldman, Jack M., and John G. Lynch (1988), "Self-Generated Validity and Other Effects of Measurement on Belief, Attitude, Intention and Behavior," Journal of Applied Psychologv, 73 (3), 421-35.

Grégoire, Yany, and Robert J. Fisher (2008), "Customer Betrayal and Retaliation: When Your Best Customers Become Your Worst Enemies," Journal of the Academv of Marketing Science, 36 (2), 247-61.

Grégoire, Yany, Daniel Laufer, and Thomas M. Tripp (2010), “A Comprehensive Model of Customer Direct and Indirect Revenge: Understanding the Effects of Perceived Greed and Customer Power," Journal of the Academv of Marketing Science, 38 (6), 738-58.

Gulliver (2009), “Did Dave Carroll Lose United Airlines \$180m?” Economist, June 24, https://www.economist.com/gulliver/2009/07/24/did-dave -carroll-lose-united-airlines-180m.

Hayes, Andrew F. (2013), Introduction to Mediation, Moderation, and Conditional Process Analysis: A Regression-Based Approach, New York: Guilford.

- (2015), "An Index and Test of Linear Moderated Mediation," Multivariate Behavioral Research, 50 (1), 1-22.

Hillyer, Clayton, and Surinder Tikoo (1995), "Effect of Cobranding on Consumer Product Evaluations," Advances in Consumer Research, 22 (1), 123-27.

Jacoby, Jacob, and David Mazursky (1984), “Linking Brand and Retailer Images: Do the Potential Risks Outweigh the Potential Benefits?" Journal of Retailing, 60 (2), 105-22.

Kahn, Barbara E., Alexander Chernev, Ulf Böckenholt, Kate Bundorf, Michaela Draganska, Ryan Hamilton, Robert J. Meyer, and Klaus Wertenbroch (2014), "Consumer and Managerial Goals in Assortment Choice and Design,” Marketing Letters, 25 (3), 293-303.

Kahn, Barbara E., and Donald R. Lehmann (1991), "Modeling Choice among Assortments," Journal of Retailing, 67 (3), 274-99.
Kähr, Andrea, Bettina Nyffenegger, Harley Krohmer, and Wayne D. Hoyer (2016), "When Hostile Consumers Wreak Havoc on Your Brand: The Phenomenon of Consumer Brand Sabotage," Journal of Marketing, 80 (3), 25-41.

Keller, Kevin Lane (1993), "Conceptualizing, Measuring, and Managing Customer-Based Brand Equity," Journal of Marketing, 57 (1), 1-22.

Lou, Yung-Chien, Meng-Chun Tsai, and Xiu-Hua Yan (2008), "Ingredient Branding Alliances: An Investigation of Brand Awareness and Feedback Effects," Advances in Consumer Research, 8 (January), 232-33.

Peterson, Hayley (2014), “Abercrombie CEO Is Out," Business Insider, December 9, www.businessinsider.com/abercrombie-ceo-is-out-2014-12.

Petty, Richard E., Duane T. Wegener, and Leandre R. Fabrigar (1997), "Attitudes and Attitude Change," Annual Review of Psychologv, 48 (1), 609-47.

Rao, Akshay, Lu Qu, and Robert W. Ruekert (1999), “Signaling Unobservable Product Quality through a Brand Ally," Journal of Marketing Research, 36 (2), 258-68.

Roehm, Michelle L., and Michael K. Brady (2007), "Consumer Responses to Performance Failures by High-Equity Brands," Journal of Consumer Research, 34 (4), 537-45.

Roehm, Michelle L., and Alice M. Tybout (2006), "When Will a Brand Scandal Spill Over, and How Should Competitors Respond?" Journal of Marketing Research, 43 (3), 366-73.

Simmons, Carolyn J., Barbara Bickart, and Lauranne Buchanan (2000), "Leveraging Equity across the Brand Portfolio," Marketing Letters, 11 (3), 210-20.

Simonin, Bernard L., and Julie A. Ruth (1998), "Is a Company Known by the Company It Keeps? Assessing the Spillover Effects of Brand Alliances on Consumer Brand Attitudes," Journal of Marketing Research, 35 (1), 30-42.

Skowronski, John J., and Donal E. Carlston (1989), "Negativity and Extremity Biases in Impression Formation: A Review of Explanations," Psuchological Bulletin, 105 (1), 131-42.

Smith, Amy K., and Ruth N. Bolton (1998), “An Experimental Investigation of Customer Reactions to Service Failure and Recovery Encounters: Paradox or Peril?” Journal of Service Research, 1 (1), 65-81.

Smith, Robert E., and William R. Swinyard (1982), "Information Response Models: An Integrated Approach," Journal of Marketing, 46 (1), 8193.

Spears, Nancy, and Surendra N. Singh (2004), "Measuring Attitude toward the Brand and Purchase Intentions," Journal of Current Issues and Research in Advertising, 26 (2), 53-66.

Sullivan, Mary (1990), "Measuring Image Spillovers in Umbrella-Branded Products," Journal of Business, 63 (3), 309-29.

Tax, Stephen S., Stephen W. Brown, and Murali Chandrashekaran (1998), "Customer Evaluations of Service Complaint Experiences: Implications for Relationship Marketing," Journal of Marketing, 62 (2), 60-76.

Taylor, Kate (2017), “An Anti-Trump Movement Is Calling for the Boycott of These 27 Retailers," Business Insider, February 28, http:// www.businessinsider.com/trump-boycott-retailers-sell-trump-products -2017-1.

Trefis Team (2014), “Abercrombie and Fitch's CEO Mike Jeffries to Step Down Immediately," Forbes, December 10, http://www.forbes.com/sites /greatspeculations/2014/12/10/abercrombie-and-fitchs-ceo-mike-jeffries -to-step-down-immediately/.

Votolato, Nicole L., and H. Rao Unnava (2006), "Spillover of Negative Information on Brand Alliances," Journal of Consumer Psychology, 16 (2), 196-202. 
Wojciszke, Bogdan, Roza Bazinska, and Marcin Jaworski (1998), "On the Dominance of Moral Categories in Impression Formation," Personalitv and Social Psychologv Bulletin 24 (12), 1245-57.

Wojciszke, Bogdan, Hanna Brycz, and Peter Borkenau (1993), "Effects of Information Content and Evaluative Extremity on Positivity and Negativity Biases," Journal of Personality and Social Psychology, 64 (3), 327 55.

Xia, Lan, Kent B. Monroe, and Jennifer L. Cox (2004), “The Price Is Unfair! A Conceptual Framework of Price Fairness Perceptions," Journal of Marketing, 68 (4), 1-15.
Xie, Yi, and Siqing Peng (2009), "How to Repair Customer Trust after Negative Publicity: The Roles of Competence, Integrity, Benevolence, and Forgiveness," Psychologv and Marketing, 26 (7), 572-89.

Zhang, Lin, and Ronald D. Taylor (2009), "Exploring the Reciprocal Effect of Negative Information of Brand Extensions on Parent Brand," Marketing Management Journal, 19 (1), 1-15.

Zhao, Yin, Ying Zhao, and Kristiaan Helsen (2011), “Consumer Learning in a Turbulent Market Environment: Modeling Consumer Choice Dynamics after a Product-Harm Crisis," Journal of Marketing Research, 48 (2), 255-67. 


\title{
How Should Retailers Deal With Consumer Sabotage of a Manufacturer Brand?
}

\author{
Bettina Nyffenegger, Andrea Kähr, Harley Krohmer, and Wayne D. Hoyer
}

\author{
Web Appendix
}




\section{WEB APPENDIX A: STIMULI FOR THE SCENARIO-BASED EXPERIMENTS \\ Description of Stimuli of Study 1}

Assortment Size Manipulation, Broad Assortment. The sports retailer Top Sport has stores all over Germany and offers a broad variety of sporting goods in the areas of fitness, running, soccer, and outdoor and winter sports. In addition, customers can also find a range of products for badminton, basketball, boxing, swimming, volleyball, and yoga.

With its product assortment, Top Sport corresponds to the demand for high quality products and provides high value for money. Customers' desires are highly important to Top Sport; customers get immediate and competent support and advice. As a responsible company, Top Sport treats its suppliers and partners fairly. The stores of Top Sport are situated at good locations and stand out for their pleasant and inviting atmosphere.

Top Sport offers a very broad assortment (i.e., many products and brands) and sells a very large amount of brands. In the area of running shoes for example, the retailer offers 35 different manufacturer brands and more than 150 running shoe models-one of them is the brand Speedy Run.

Assortment Size Manipulation, Narrow Assortment. The sports retailer Top Sport has stores all over Germany and offers a selected choice of running shoes, functional textiles, and accessories with a focus on running.

With its product assortment, Top Sport corresponds to the demand for high quality products and provides high value for money. Customers' desires are highly important to Top Sport; customers get immediate and competent support and advice. As a responsible company, Top Sport treats its suppliers and partners fairly. The stores of Top Sport are situated at good locations and stand out for their pleasant and inviting atmosphere.

Top Sport offers a very small assortment (i.e., few products and brands) and sells a very small amount of brands. In the area of running shoes for example, the retailer only offers 5 different manufacturer brands and about 20 different running shoe models-one of them is the brand Speedy Run. 


\section{Manipulation of Performance-Based CBS Manipulation of Value-Based CBS}

Peter Zumstein

March 12 at $6.30 \mathrm{pm} \cdot \mathrm{e}$

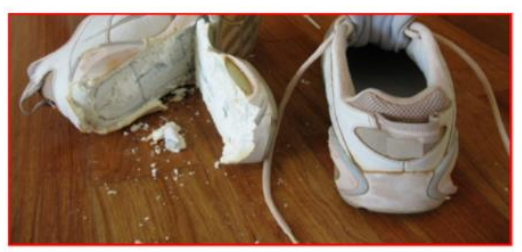

Lousy Quality of the Running Shoes with Speedy Run ATTENTION: After a very short time, the sole of the running shoes from Speedy Run detaches from the shoe! BOYKOTTSPEEDYRUN.COM

I've recently bought a really expensive pair of running shoes from Speedy Run. Already after a few weeks, the sole started crumbling and finally detached from the shoe entirely; just when I was out all day. I chafed my heel because of that! A nasty inflammation was the result because pieces of the shoe's fabric entered the wound. That simply must not be possible! l've made a video of it - this Speedy Run shoe is a piece of junk. Have a look at it.

When I complained to Speedy Run they "generously" offered me that they put new soles on the shoes - for the price of 50 Euro. That's just about the limit! They should have replaced the damage at the very least.

That clearly has to stop. Such a lousy quality must not be tolerated. don't want to deal with Speedy Run anymore and I certainly will never ever buy products of Speedy Run again.

More information about this story and the lousy quality of Speedy Run on my anti-SpeedyRun-blog.

So, guys, help me and boycott Speedy Run!!! Thank you very much for your support!

\#BoycottSpeedyRun \#lousyquality@SpeedyRun

\#NeverEverSpeedyRun

Like · Comment · Share

[3 8741 people like this.

$\Rightarrow 546$ shares

Petra Frei This is really annoying! That must have hurt quite much. I had also some running shoes of Speedy Run at home. But l've never really worn them because they are very uncomfortable. I just got rid of them now! Never ever products of Speedy Run again.

Like - Reply · $3251 \cdot$ March 12 at 9.13 pm

Markus Schild What a shame! Again another sports manufacturer that offers lousy quality at a high price. I can't understand that! Never ever Speedy Run again.

Like - Reply $2745 \cdot$ March 13 at $12.31 \mathrm{pm}$
Peter Zumstein

March 12 at $6.30 \mathrm{pm} \cdot \mathrm{e}$

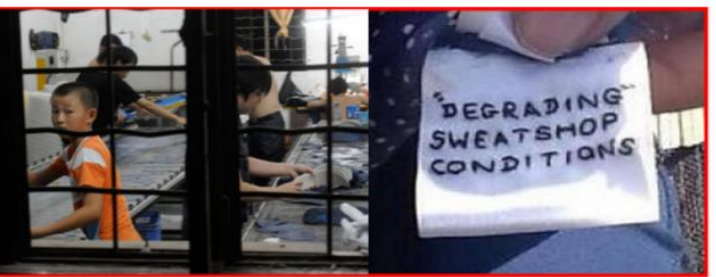

Degrading Working Conditions with Speedy Run CALL FOR ACTION: Speedy Run's running shoes are manufactured under degrading conditions!

BOYKOTTSPEFDYRLIN CON

You may have read this article in the "Spiegel": Speedy Run pays dumping wages to produce its running shoes. Workers report burnings due to cable opens, contaminated water, and extreme working pressure: "At the moment, we are often not even allowed to go to the toilette," quoted the magazine an ironer. What is worse is that there are minors working in the factories. This means that instead of going to school, they have to produce running shoes for Speedy Run under lousy working conditions. This is a catastrophe!

Also, you can't imagine what has happened to me. On the label of a shirt I recently bought from Speedy Run, I found a cry for help from a worker. It said "Degrading Sweatshops Conditions." We need to consider for a moment what this means. These poor women need to be enormously desperate.

We have to do something. We mustn't tolerate such an irresponsible and immoral behavior that disrespects human dignity. I don't want to deal with Speedy Run anymore and I certainly will NEVER EVER buy products of Speedy Run again.

More information about this story and the abominable working conditions on my blog. Here is also a video, in which I collected the facts about the hideous working conditions

So, guys, help me! Don't buy products of Speedy Run!!! Thank you very much for your support!

\#BoycottSpeedyRun \#RespectHumanRights \#RespectDignityEqualityFairness

Like $\cdot$ Comment $\cdot$ Share

8741 people like this.

$\Rightarrow 546$ shares

Petra Frei This is a disgracel I'm shocked and I will NEVER EVER buy products of Speedy Run again. I just got rid of my own Speedy Run running products of Speedy Run again. I just got rid of my own Speedy R
shoes. I won't support a company that behaves that unethically. Like - Reply · $3251 \cdot$ March 12 at 9.13 pm

Markus Schild What a shame! Again another manufacturer that doesn't care about social responsibility and only focuses on profit. How can one be so reckless?! I can't understand such behavior! Like - Reply - 2745 - March 13 at 12.31 pm 
Assortment Decision Manipulation, Delisting. Due to the negative incidents and some fierce customer reactions, the retailer Top Sport takes the manufacturer brand out of its shelves and, thus, eliminates the brand from its assortment.

Assortment Decision Manipulation, Continuation. Despite the negative incidents and some fierce customer reactions, the retailer Top Sport does not eliminate the manufacturer brand from its assortment and, thus, continues to sell the brand.

\section{Description of Stimuli of Study 2}

Assortment Size Manipulation, Broad Assortment. The retailer Vidam has supermarkets all over Germany, Switzerland, and Austria. Vidam offers a range of different products, especially food and everyday items. Thereby, Vidam not only offers branded products of various manufacturers but also private labels (i.e., products that are manufactured under Vidam's direction and sold under their name).

With its product assortment, Vidam corresponds to the demand for high quality products and provides high value for money while still carefully considering environmental aspects. Customers' desires are highly important to Vidam; customers always get immediate and competent support and advice. The supermarkets are situated at good locations and stand out for their pleasant and inviting atmosphere.

Vidam offers a very broad assortment (i.e., many products and brands) and sells a very large amount of brands. In the category of sweets for example, the retailer offers 35 different manufacturer brands of chocolate products-one of them is the brand Zeidel.

Assortment Size Manipulation, Narrow Assortment. The retailer Vidam has supermarkets all over Germany, Switzerland, and Austria. Vidam offers a range of different products, especially food and everyday items. Thereby, Vidam not only offers branded products of various manufacturers but also private labels (i.e., products that are manufactured under Vidam's direction and sold under their name).

With its product assortment, Vidam corresponds to the demand for high quality products and provides high value for money while still carefully considering environmental aspects. Customers' desires are highly important to Vidam; customers always get immediate and competent 
support and advice. The supermarkets are situated at good locations and stand out for their pleasant and inviting atmosphere.

Vidam offers a very small assortment (i.e., few products and brands) and sells a very small amount of brands. In the category of sweets for example, the retailer only offers 5 different manufacturer brands of chocolate products-one of them is the brand Zeidel.

\section{Manipulation of Performance-Based CBS Manipulation of Value-Based CBS}

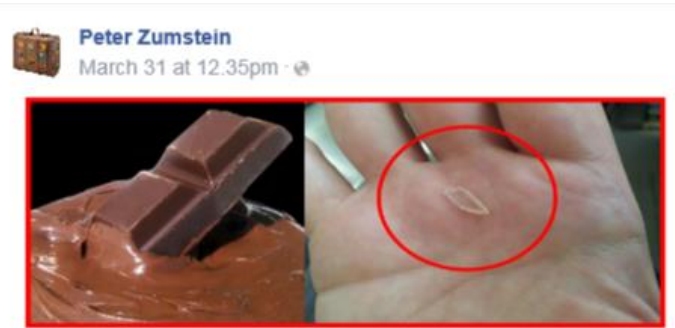

Pieces of Plastic in Zeidel's Chocolate Bars Zeidel's production of chocolate bars has severe defects and endangers the health of its customers. In their chocolate bars, pieces of plastic were...

BOYKOTIZEIDEL. COM

ATTENTIONI I have broken a tooth while eating a stupid chocolate bar of ZeideII!! Watch out when you eat that! Guys, these chocolate bars are dangerous - one could suffocate on thesel More information about the severe production defects of Zeidel's chocolate bars in my blog! \#ProductionDefects \#ZeidellsDangerous

Like · Comment - Share

$\$ 8471$ people like this.

$\Rightarrow 783$ shares

Petra Frei On Peter, that sounds terriblel Actually, I like eating these chocolate bars but that is incredible! I checked my cupboard after reading your posts and threw all chocolate of Zeidel away. That's enough $-I$ won't EVER again buy a chocolate bar of Zeidell Like - Reply - $\$ 3251$ - April 3 at 18.41 pm

Markus Schild What a shame! Again another manufacturer that doesn't use reasonable carel Why don't they just comply to the rules and work carefully? I can't understand this! \#NeverAgainZeidel \#Don'TWanttoSuffocateonaPieceofPlastic Like - Reply - S $2789 \cdot$ April 7 at 09.14am

Write a comment

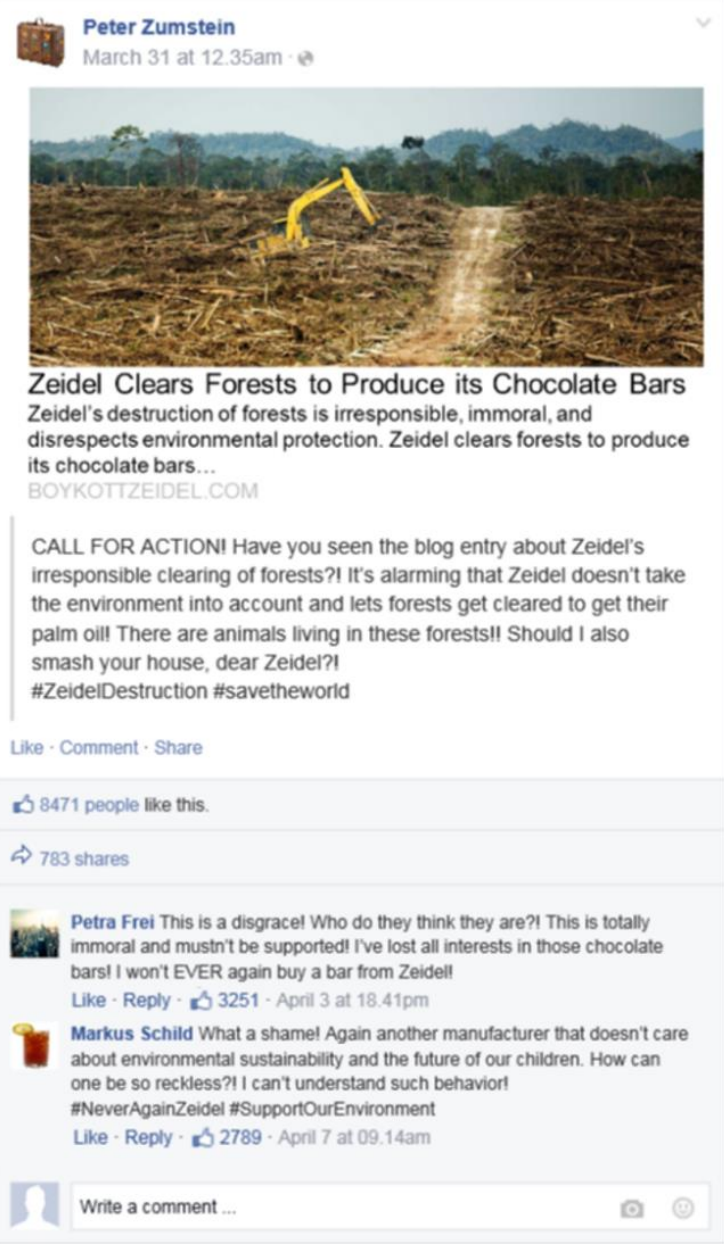

Assortment Decision Manipulation, Delisting. Due to the negative incidents and some fierce customer reactions, the retailer Vidam takes the manufacturer brand out of its shelves and, thus, eliminates the brand from its assortment.

Assortment Decision Manipulation, Continuation. Despite the negative incidents and some fierce customer reactions, the retailer Vidam does not eliminate the manufacturer brand from its assortment and, thus, continues to sell the brand. 


\section{WEB APPENDIX B: ADDITIONAL INFORMATION ON STUDIES 1-3}

\section{Pretest of the Scenarios for the Assortment Size and Type of CBS for Study 1}

To ensure that participants perceived the assortment size and type of CBS as intended, we conducted a pretest with the crowdsourcing platform Clickworker among 73 participants from Austria, Germany, and Switzerland (56\% male, $\left.\mathrm{M}_{\mathrm{age}}=32\right)$. We first showed participants a general description of the sports retailer Top Sport and then randomly assigned participants to either the small or broad assortment manipulation and to the performance- or value-based sabotage case of the manufacturer brand Speedy Run. The manipulation check measures for assortment size and type of CBS were the same as in study 1. As further control variable for the assortment size scenarios, we measured the perceived image of the sports retailer Top Sport with a four-item scale adapted from Kremer and Viot (2012). Furthermore, we also measured the following control variables for the CBS scenarios: failure severity with the three-item scale and dissatisfaction with the two-item scale adapted from Grégoire and Fisher (2008), fairness with the two-item scale adapted from Bolton, Keh, and Alba (2010), blame attribution with the three-item scale from Grégoire, Laufer, and Tripp (2010), and credibility with a two-item scale adapted from Bonifield and Cole (2007). Finally, participants indicated their sex and age and were presented a debriefing (see Table B.1 in Web Appendix B for all items and Cronbach's alpha).

Unless indicated otherwise, we used seven-point Likert scales ranging from 1 = "completely disagree" to $7=$ "completely agree" for all measures in this study. We conducted a 2 (assortment size) x 2 (CBS type) Anova for each manipulation check measure and control variable to test whether the manipulations varied as intended. The first two Anovas examined the manipulation check measure and the control variable for the assortment size manipulation. The first Anova with the assortment size measure as dependent variable revealed that participants in the broad assortment condition reported significantly higher values on the assortment size measure than participants in the narrow assortment condition $(E M M=5.85, \mathrm{SE}=.22$ vs. $E M M=2.28, \mathrm{SE}$ $=.20 ; F(1,69)=143.17, p<.001)$. The second Anova with the retailer image as dependent variable showed that there was no significant difference in the image perception across the two assortment size conditions $(p=.65)$, as intended. Two further Anovas with the two manipulation check measures (performance- and value-based CBS) as dependent variables were run to test the CBS type manipulation: The performance-based brand sabotage was perceived as significantly 
stronger addressing the brand's performance compared to the value-based brand sabotage (EMM $=6.26, \mathrm{SE}=.24$ vs. $E M M=2.39, \mathrm{SE}=.23 ; F(1,69)=137.35, p<.001)$. On the other hand, the value-based brand sabotage was assessed as stronger addressing the personal values of the consumer than the performance-based brand sabotage $(E M M=6.62, \mathrm{SE}=.22$ vs. $E M M=3.59, \mathrm{SE}=$ $.23 ; F(1,69)=94.19, p<.001)$. With regard to the CBS scenarios, the performance-based and the value-based sabotage scenarios showed higher values on the CBS scale than the midpoint of the scale (midpoint $=4.0)$ and, thus, were perceived as $\mathrm{CBS}(M=5.66, \mathrm{SE}=.21$ vs. $M=5.61, \mathrm{SE}$ $=.21)$. The difference between the two scenarios was not significant $(F(1,71)=.04, p=.84)$. Concerning the control variables for the CBS scenarios, we run five further Anovas with each control variable as dependent variable. As intended, these analyses revealed that there were no significant differences across the two CBS scenarios with regard to perceived dissatisfaction, blame attribution, fairness, failure severity, and credibility ( $p s \geq .10)$.

\section{Pretest of the Scenarios for the Assortment Size and Type of CBS for Study 2}

To ensure that the stimuli were perceived as intended, we conducted again a pretest with the platform Clickworker among 99 participants from Austria, Germany, and Switzerland (57\% male, $M_{\text {age }}$ =34). We again first showed participants the general description of the retailer, followed by our manipulation of the assortment size and type of CBS. We employed the same measures as in the pretest of study 1 and asked participants to report their sex and age (see Table B.1 in Web Appendix B for all items and Cronbach's alpha). They were then presented a debriefing.

We conducted a 2 (assortment size) x 2 (CBS type) Anova for each manipulation check measure and control variable to ensure that the manipulations worked as intended. For the first two Anovas concerning the assortment size manipulation, we used the assortment size measure (manipulation check) and the retailer image (control variable) as dependent variable. The first Anova showed that participants in the broad assortment condition reported significantly higher scores on the assortment size scale than in the condition with a narrow assortment $(E M M=6.34$, $\mathrm{SE}=.16$ vs. $E M M=2.17, \mathrm{SE}=.14 ; F(1,95)=388.03, p<.001)$. The second Anova with the retailer image as dependent variable revealed that participants did not perceive the image differently across the broad and narrow assortment condition $(p=.59)$, as intended. With regard to the manipulation of CBS type, we ran two Anovas with the manipulation check measures (performance- and value-based CBS) as dependent variables: The performance-based CBS was more 
strongly perceived as dealing with performance than the value-based $(E M M=5.67, \mathrm{SE}=.22 \mathrm{vs}$. $E M M=3.22, \mathrm{SE}=.21 ; F(1,95)=64.04, p<.001)$. On the other hand, the value-based CBS was more strongly perceived as addressing values than the performance-based CBS $(E M M=5.41, \mathrm{SE}$ $=.22$ vs. $E M M=4.67, \mathrm{SE}=.23 ; F(1,95)=5.46, p<.05)$. Both scenarios displaying value- and performance-based brand sabotage showed values higher than the mean value of the CBS scale, meaning that participants perceived these as brand sabotage and the difference between the two scenarios was not significant $(M=5.57, \mathrm{SE}=.19$ vs. $M=5.70, \mathrm{SE}=.17 ; F(1,97)=.25, p=.62)$. Finally, we ran five Anovas with the control variables as dependent variables. As intended, the two brand sabotage scenarios did not differ significantly in perceived dissatisfaction, blame attribution, fairness, failure severity, and credibility ( $p s \geq .17$ ).

\section{Study 3}

Study 3 examined more nuanced scenarios of performance- versus value-based CBS cases in the watch industry to determine how the personal values of consumers influence the interplay between the retailer's assortment decision and the type of CBS on consumers' attitude toward the retailer.

Method. We conducted an online experiment on the platform Clickworker with a two factorial between-subjects design with a fictitious brand in the watch industry. More specifically, we used a 2 (assortment decision of the retailer: delisting vs. continuing) x 2 (type of CBS: value-based vs. performance-based) factorial design with a control group who was only shown some general information about the retailer (hanging control).

In our study, 670 consumers $\left(55 \%\right.$ male, $\left.\mathrm{M}_{\mathrm{age}}=34\right)$ took part. The structure of the experiment followed the same logic as of studies 1 and 2 but without the manipulation of the assortment size. Participants read three blocks of stimuli containing some general information about the retailer, followed by the manipulation of the type of CBS and the retailer's reaction. Participants were again randomly assigned to one of the two conditions for each scenario. In the first block, they read the following general description about the fictitious retailer Schneeberger. To the control group, only this general description was shown (without any manipulation).

The watch and jewelry store Schneeberger is a leading Swiss company with shops in Switzerland, Germany and Austria. The company offers good value for money and stands for excellent service quality. 
Schneeberger's assortment of watches and jewelry ranges from classic top and premium brands such as Longines, Omega, Tissot and Swatch to fashion brands such as Fossil, Guess, Thomas Sabo, and Swarovski.

In the second block, participants read one of the two following Facebook posts of a consumer sabotaging the brand Beatus, a manufacturer of premium watches (see manipulations of the performance- vs. value-based CBS below). In both the value- and the performance-based scenario, a Facebook post by the saboteur was shown with a picture of an advertisement of the brand Beatus followed by a description of his brand experience. This description included the same number of paragraphs and the same amount of arguments for both scenarios to omit any confounds. Finally, in the third section, we manipulated the retailer's reactions. We used the same manipulation as in study 1 and 2 (see Web Appendix A).

Following the scenarios, participants had to respond to the manipulation checks for the type of CBS and assortment decision and to report their attitude toward the retailer as dependent variable, which were the same as in study 1 and 2. In addition, we measured consumers level of sexism with the short version of the benevolence sexism inventory from Rollero, Glick, and Tartaglia (2014) and consumers' quality consciousness with the four-item scale from Shim and Gehrt (1996). These two constructs refer to consumers' personal values which may moderate the interplay between a retailer's assortment decision and type of CBS on consumers' attitude. We then asked participants to report their sex, age, and the objective of this study. Again, we presented a debriefing (see Table B.1 in Web Appendix B for all items and Cronbach's alpha).

Pretest. Again, we conducted a pretest of our CBS scenarios to ensure that they were perceived as intended. We recruited 119 participants from the platform Clickworker from Austria, Germany, and Switzerland (51\% female, $\left.\mathbf{M}_{\mathrm{age}}=37\right)$. We first presented participants the general description of the retailer and then randomly assigned them to one of the two CBS scenarios. Subsequently, we asked them to respond to the manipulation checks and control variables, which were the same as in study 1 and 2. Finally, participants reported their sex and age and were presented a debriefing (see Table B.1 in Web Appendix B for all items and Cronbach's alpha).

We conducted one-way independent Anovas to test if the manipulated factors varied as intended. The performance-based CBS was more strongly perceived as dealing with performance than the value-based CBS $(M=5.64, \mathrm{SE}=.20$ vs. $M=1.79, \mathrm{SE}=.16 ; F(1,117)=241.46, p<$ 
.001). Also, the performance-based CBS was less perceived as addressing values than the valuebased CBS $(M=2.86, \mathrm{SE}=.27$ vs. $M=5.76, \mathrm{SE}=.14 ; F(1,76)=92.48, p<.001)$.

\section{Manipulation of Performance-Based CBS}

Jan Weibel

November 7 at $6.33 \mathrm{pm}$ -

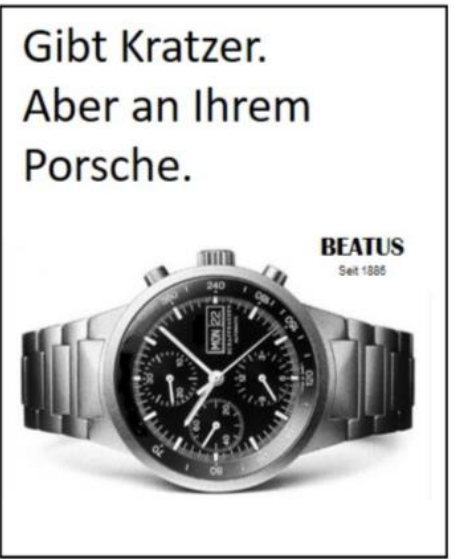

Quality problems with BEATUS - scratches on my premium-watch

Four months ago, I bought a BEATUS watch. However, my joy with this purchase only lasted briefly. When I recently hurried to catch my train, my new watch inexplicably slipped from my wrist and fell to the floor. The case of my supposedly scratch-resistant watch was then totally ruined.

This is unbelievable. Such an expensive watch and it is not even scratch-resistant. This is especially bad as BEATUS even boasts in its ads about how scratch-resistant this watch is. Subsequently, I filed a complaint with BEATUS and sent it to the company for repair work.

However, I would never have expected the kind of response I would get from a premium brand such as BEATUS. After I waited three full months to get my watch back, I received a rude awakening. The scratches had been removed, however, without any prior warning, they charged me 7000 euros for the repair work. Their explanation was: "damage due to improper usage is not covered by the international BEATUS quarantee." When I complained to their customer service department, they dismissed me by saying that I should read their guarantee guidelines

With a premium watch such as BEATUS that advertises how scratchresistant their watch is, I expect that the watch would not be easily scratched when it drops to the floor. And if this does happen nevertheless, they should clearly cover the repair costs.

I won't support a watch brand that appears to have obvious quality problems and offers such a poor customer service. Help me and boycott BEATUS!

You can find my experience as well as all correspondence with BEATUS on my blog (boycottBEATUS. com) so that you can convince yourself what quality issues BEATUS has

\#BEATUSScratchedWatch \#PoorCustomerService \#QualityProblemsBEATUS

Like - Comment. Share

$\$ 8471$ like this

$\Rightarrow 783$ shares

Jule Schmidt Oh no, somebody just lost all his joy with his new watch. This is outrageous! An expensive watch such as this cant afford to engage in is outrageous! An

Like - Reply - os 352 - November 8 at $1.42 \mathrm{pm}$

Write a comment

\section{Manipulation of Value-Based CBS}

Jan Weibel

November 7 at $6.33 \mathrm{pm}$ - a

\section{Fast so schön \\ wie eine Frau. \\ Tickt aber richtig.}

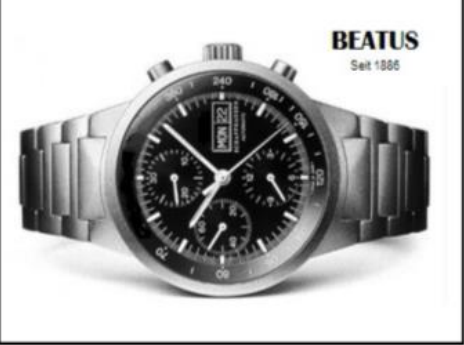

BEATUS' incredibly sexist advertisement

Have you seen the latest advertisements from BEATUS? When I saw the first ad I thought this must be fake. But they are actually reall The watch manufacturer BEATUS advertises with sexist statements such as "As beautiful as a woman But ticks right." or "Too good to be worn when shopping, washing, cleaning or changing diapers." And the best thing: one can even order these terrible ads as posters for 30 euros.

Ironically, I just happened to buy a BEATUS watch last month. At that time, I didn't realize that macho pigs are behind this watch. What a backward, patriarchal company - they have certainly not arrived in the 21 st century. In any case, I can't wear this watch anymore. I'm NOT a macho pig.

So I filed a complaint to BEATUS. Do you know what kind of response Igot?:

-Our campaign provokes. That's what it should do. Because BEATUS watches deserve to stand out. Not only on the wrist. The BEATUS. campaign is based on our mission to produce watches for men. But more and more women wear BEATUS watches, thereby storming one of the last remaining male bastions. Our watch should be for men, representing a plea for the masculinity."

So, BEATUS deliberately doesn't want women to wear their watches. I won't support a watch brand that discriminates women as overtly. Help me and boycott BEATUS!

I compiled various sexist ads of BEATUS on my blog (boycottBEATUS.com) so that you can convince yourself about this discriminating, sexist company.

\#BEATUSmachos \#AgainstDiscriminatingAds \#BEATUSsexist

Like - Comment - Share

8471 people like this.

$\Rightarrow 783$ shares

Jule Schmidt Well, then BEATUS won't need to wonder why no one wants to wear their brand. I am very much inclined to take legal actions and go to the Swiss Commission of Fair Trading Such macho behavior mustn't be tolerated!

Like - Reply - 352 - November 8 at $1.42 \mathrm{pm}$ 
Both scenarios displaying value- and performance-based brand sabotage showed values higher than the mean value of the scale, meaning that participants perceived these as brand sabotage and the difference between the two scenarios was not significant $(M=4.98, \mathrm{SE}=.16, M=$ $4.67, \mathrm{SE}=.18) ; F(1,117)=1.67, p=.20)$. As intended, the two brand sabotage scenarios did not differ significantly in perceived dissatisfaction, blame attribution, fairness, failure severity, and credibility $(p s>.12)$.

Results of the Main Study. We conducted two 2 (CBS type) x 2 (assortment decision) Anovas to ensure that the manipulation of CBS type worked as intended. The first Anova revealed that the performance-based CBS scenario was perceived as more strongly addressing the brand's performance compared to the value-based scenario $(E M M=5.42, \mathrm{SE}=.09$ vs. $E M M=1.87, \mathrm{SE}=.08$; $F(1,541)=979.17, p<.001)$. On the other hand, participants assessed the value-based CBS scenario as stronger addressing values than the performance-based scenario $(E M M=5.30, \mathrm{SE}=.10$ vs. $E M M=3.17, \mathrm{SE}=.11 ; F(1,541)=194.54, p<.001)$. To make sure that participants perceived the performance-based and value-based scenarios as CBS, we examined whether they reached higher scores on the CBS scale than the midpoint of the scale, which was true for both the performance-based and the value-based CBS scenarios and the difference between the two was not significant $(M=4.78, \mathrm{SE}=.10$ vs. $M=4.74, \mathrm{SE}=.08 ; F(1,543)=.13, p=.72)$. To test whether participants understood whether or not the retailer continued to carry the sabotaged brand, they had to indicate whether the retailer delisted or continued the brand by choosing the respective answer option. Using a full-factorial binary logistic regression (including the CBS type condition as predictor), the continuation $(=0)$ versus delisting $(=1)$ condition served as significant predictor of the assessment of the assortment decision $(\mathrm{B}=6.64, \mathrm{SE}=.50 ; p<.001$; odds ratio $=762.01,95 \%$ Confidence Interval $[\mathrm{CI}]=[285.80,2031.67] ; \mathrm{R}^{2}=.77$ (Hosmer \& Lemeshow), .66 (Cox \& Snell), .88 (Nagelkerke); Model $\left.\chi^{2}(2)=556.741, p<.001\right)$.

We conducted a one-way independent ANOVA to test whether the sabotage scenarios significantly decreased consumers' attitude toward the retailer compared to the control group. Participants in the CBS condition reported significantly lower scores in brand attitude than the control group $(M=4.90, \mathrm{SE}=.06$ vs. $M=5.41, \mathrm{SE}=.08 ; F(1,279)=27.39, p<.001)$ (see Table B.4 in Web Appendix B). The result did not change whether or not we included participants' sex and age as control variables. For the subsequent analyses, the control group was excluded. 
To test our main effect of the assortment decision on consumers' brand attitude and to examine how the type of CBS and consumers' personal values influence this effect, we conducted a two-way ANOVA. The main effect of the assortment decision (continuation vs. delisting) on consumers' brand attitude was significant $(F(1,541)=20.33, p<.001)$. Participants confronted with the decision to delist the sabotaged brand reported significantly higher scores in their attitude toward the retailer brand than those confronted with its continuation $(E M M=5.16, \mathrm{SE}=.08 \mathrm{vs}$. $E M M=4.90, \mathrm{SE}=.08)$. The interaction effect of the assortment decision with the type of CBS on consumers' attitude was not significant $(F(1,541)=.77, p=.38)$. The result did not change whether or not we included participants sex and age as control variables.

In a next step, we probed how the effect of the retailer's assortment decision on consumers' attitude depends on the type of CBS and the consumers' personal values. As the moderating variables were continuous, we conducted moderation analyses using ordinary least squares path analysis with PROCESS model 3 (bootstrapping of 10,000 samples; Hayes 2013). We found significant three-way interactions with the assortment decision (continuation $=0$, delisting $=1$ ) as independent variable, brand attitude as dependent variable and type of CBS (performance-based $=0$, value-based $=1$ ) as moderator of this effect, whose effect was again moderated by the consumers' personal values (sexism: $\mathrm{b}_{7}=-.43, \mathrm{SE}=.19 ; t(537)=-2.26, p<.05$, quality consciousness: $\left.\mathrm{b}_{7}=-.48, \mathrm{SE}=.21 ; t(537)=-2.25, p<.05\right)($ see Tables B.7 and B.8, Web Appendix B). Tests of conditional two-way interactions of the assortment decision with the consumers' personal values revealed that they were only significant for value-based CBS (sexism: $\mathrm{B}=-.47 ; F(1$, $537)=17.52, p<.001$; quality consciousness: $\mathrm{B}=-.29 ; F(1,537)=5.70, p<.05)$ but not for performance-based CBS (sexism: $\mathrm{B}=-.05 ; F(1,537)=.09, p=.76$; quality consciousness: $\mathrm{B}=.18$; $F(1,537)=1.12, p=.29)$. To decompose the two significant interactions of the assortment decision with the consumers' personal values (i.e., sexism and quality consciousness) on consumers' attitude toward the retailer brand for the value-based CBS, we used the Johnson-Neyman technique to identify the range(s) of the benevolent sexism and quality consciousness for which the simple effect of the assortment decision on consumers' brand attitude was significant. With regard to benevolent sexism, this analysis revealed that there was a significant positive effect for the delisting versus continuation on brand attitude for values of benevolent sexism below 3.97 $\left(\mathrm{B}_{\mathrm{JN}}=.29, \mathrm{SE}=.15 ; p=.05\right)$ and a negative effect for values above $5.57\left(\mathrm{~B}_{\mathrm{JN}}=-.47, \mathrm{SE}=.24 ; p\right.$ $=.05$ ) but no significant effect in between these two values (see Figure 1, Web Appendix B). 
With regard to quality consciousness, the analysis showed that there was a significant positive effect for the delisting versus continuation on brand attitude for values of quality consciousness below $5.82\left(\mathrm{~B}_{\mathrm{JN}}=.33, \mathrm{SE}=.17 ; p=.05\right)$ but not above this value (see Figure 2, Web Appendix $\mathrm{B}$ ). The result did not change whether or not we included participants sex and age as control variables.

Discussion. This study replicated the findings from study 1 and 2 with regard to the baseline and main effects. CBS of a manufacturer brand lowers consumers' attitude toward the related retailer. However, by delisting the brand, the retailer can mitigate this negative effect. Furthermore, this study examined more nuanced scenarios with regard to the type of CBS. With the selected scenarios, the outcomes of the retailer's response to the respective type of CBS did depend on consumers' personal values. More specifically, the retailer's decision to delist (vs. continue) the sabotaged brand only increased consumers' brand attitude in a positive when the actions of the manufacturer brand that led to the sabotage were in conflict with their personal values. When the manufacturer's actions did not contradict consumers' personal values, the assortment decision either had no affect (i.e., for quality consciousness values above 5.82) or was reversed, such that continuing the sabotaged brand was perceived in a more positive way than delisting it (i.e., for benevolent sexism values above 5.57). Thus, these results also suggest that the impact of delisting (vs. continuing) a sabotaged manufacturer brand and the corresponding interactions with type of CBS and assortment size on consumers' attitude toward the retailer (study 1 and 2) are especially valid among those consumers whose values are violated by the underlying transgression of the brand. 


\section{Panel A: Regression Lines with Johnson-Neyman Points}

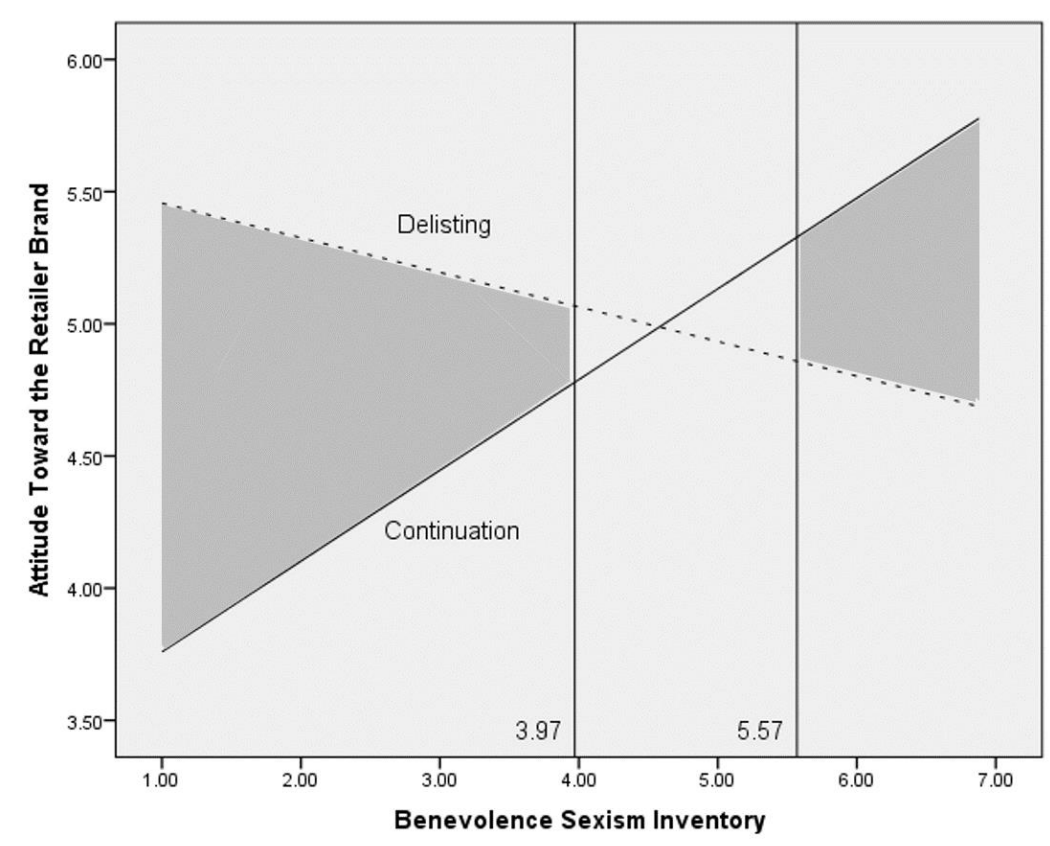

Panel B: Estimated Simple Effect of Assortment Decision with Confidence Bands

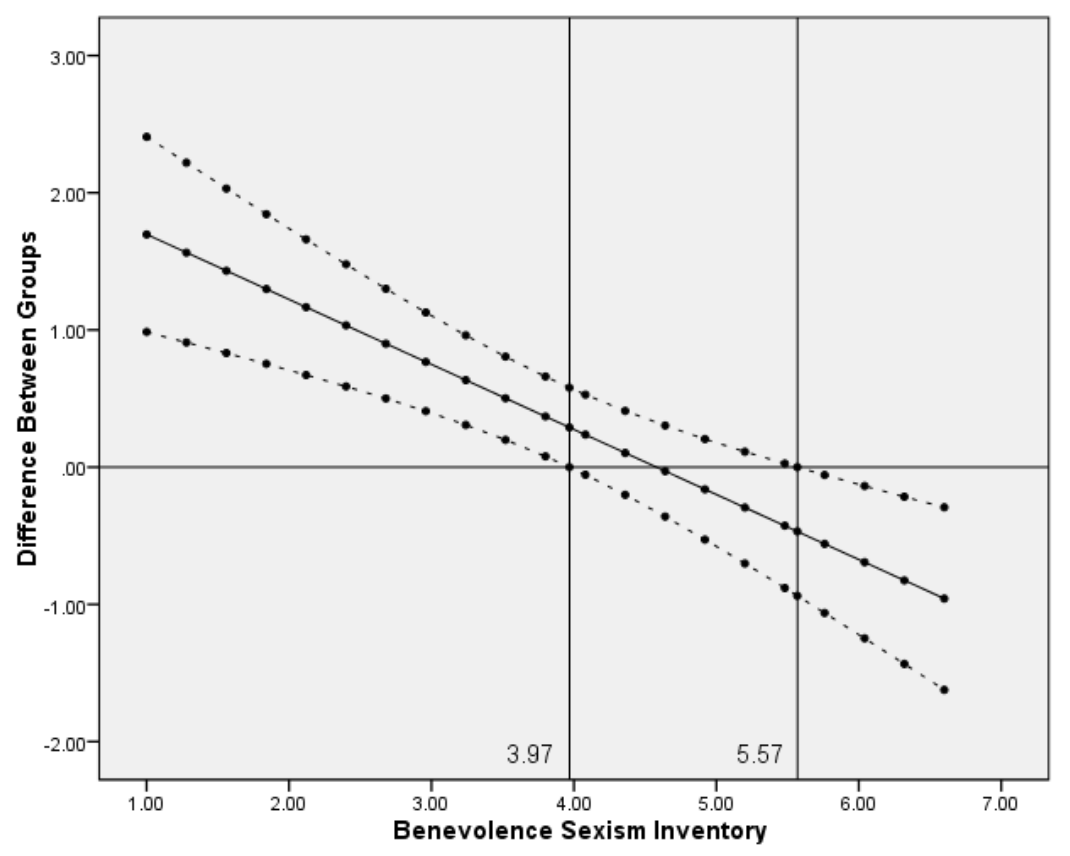

Figure 1: Three-way interaction with assortment decision, CBS type, and ambivalent benevolent sexism inventory on consumers' attitude toward the retailer brand. Panel A shows a floodlight of the region of values for the benevolent sexism inventory (filled areas below 3.97 and above 5.57) for which a spotlight test would reveal significant differences between the two model groups. Panel B shows a graph of the estimated simple effect (the distance between the two regression lines in Panel A) with confidence bands. Confidence bands are narrowest at mean benevolent sexism inventory $(M=3.67)$. The Johnson-Neyman points in Panel A align with the intersections of the confidence band and the $\mathrm{x}$-axis in Panel B. The crossover point in Panel A aligns with the intersection of the estimated simple effect and the $\mathrm{x}$-axis in Panel B. 


\section{Panel A: Regression Lines with Johnson-Neyman Point}

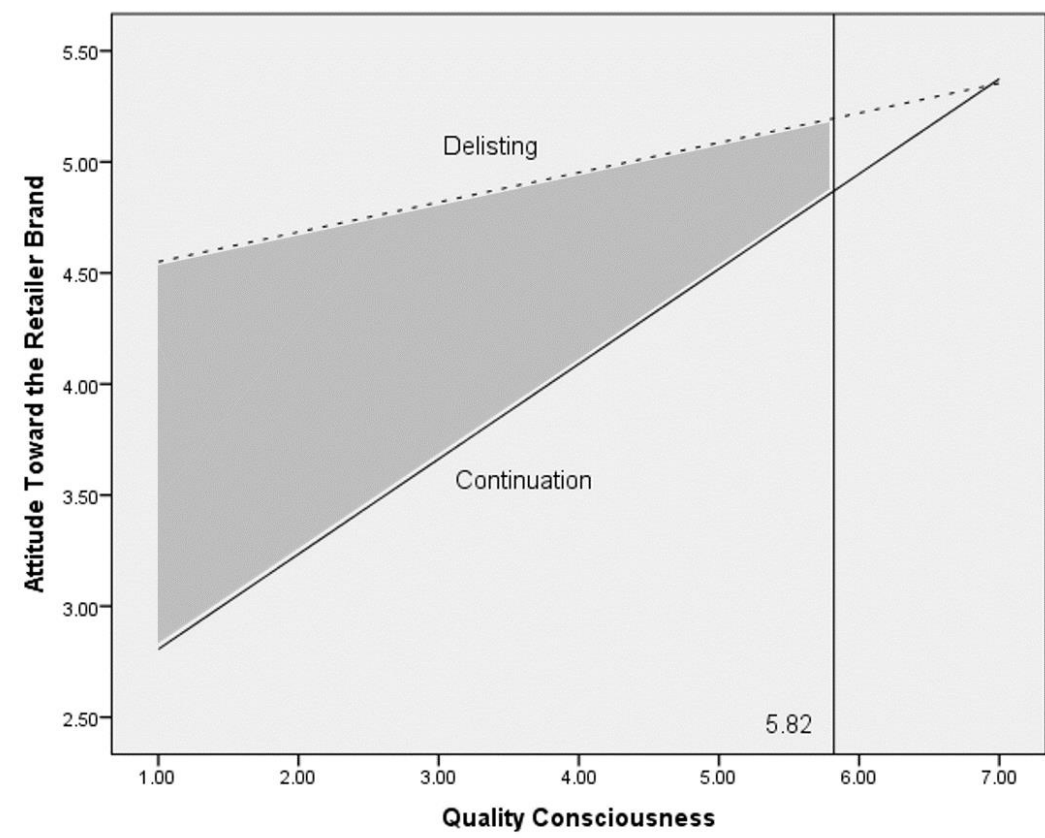

B: Estimated Simple Effect of Assortment Decision with

\section{Confidence Bands}

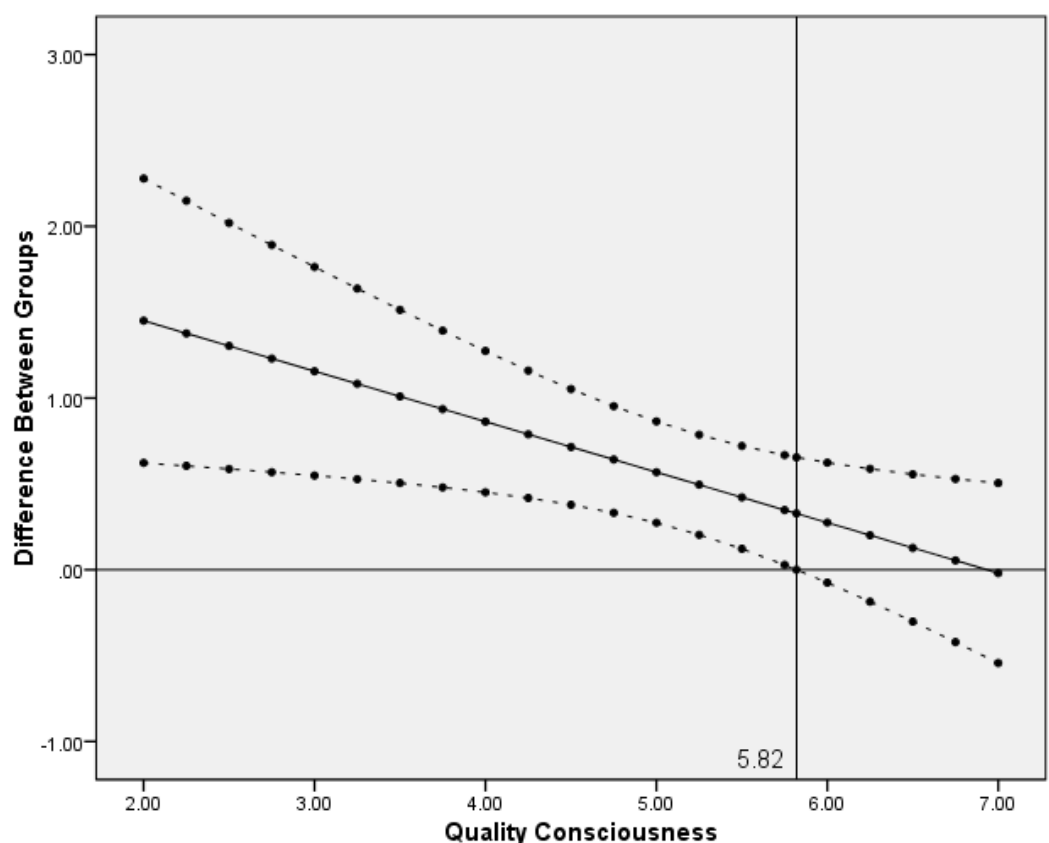

Figure 2. Three-way interaction with assortment decision, CBS type, and quality consciousness on consumers' attitude toward the retailer brand. Panel A shows a floodlight of the region of quality consciousness values (filled area below 5.82) for which a spotlight test would reveal significant differences between the two model groups. Panel B shows a graph of the estimated simple effect (the distance between the two regression lines in Panel A) with confidence bands. Confidence bands are narrowest at mean quality consciousness $(M=5.29)$. The Johnson-Neyman point in Panel A aligns with the intersection of the confidence band and the $\mathrm{X}$-axis in Panel $\mathrm{B}$. The crossover point in Panel A aligns with the intersection of the estimated simple effect and the $\mathrm{x}$-axis in Panel B. 
Table B.1. Constructs Indicators, Measurement Items, Scale Reliabilities for Studies 1-3

\begin{tabular}{|c|c|c|c|c|c|c|c|}
\hline \multirow[t]{2}{*}{ Measure } & \multirow[t]{2}{*}{ Items } & \multicolumn{4}{|c|}{ Cronbach's Alpha (a) } & \multirow[b]{2}{*}{$\begin{array}{l}\text { Pretest } \\
\text { S3 }\end{array}$} & \multirow[b]{2}{*}{$\begin{array}{c}\text { Study } \\
3\end{array}$} \\
\hline & & $\begin{array}{l}\text { Pretest } \\
\text { S1 }\end{array}$ & $\begin{array}{c}\text { Study } \\
1\end{array}$ & $\begin{array}{l}\text { Pretest } \\
\text { S2 }\end{array}$ & $\begin{array}{l}\text { Study } \\
2\end{array}$ & & \\
\hline \multicolumn{8}{|l|}{$\begin{array}{l}\text { Manipulation } \\
\text { Check }\end{array}$} \\
\hline $\begin{array}{l}\text { Assortment } \\
\text { size }^{a^{a}}\end{array}$ & $\begin{array}{l}\text { The retailer } X \text { offers... } \\
\text {... very small assortment. (1)-...a very large } \\
\text { assortment. (7) } \\
\text {...a very limited choice of products and brands. } \\
\text { (1)-... a very large choice of products and } \\
\text { brands. (7) }\end{array}$ & .95 & .97 & .95 & .98 & - & - \\
\hline $\mathrm{CBS}^{\mathrm{b}}$ & $\begin{array}{l}\text { [The saboteur] wanted to cause harm to [the } \\
\text { manufacturer brand]. } \\
\text { The goal of [the saboteur] was to cause damage } \\
\text { to [the manufacturer brand]. } \\
\text { [The saboteur] deliberately created a Facebook } \\
\text { and blog post to impair other consumers' percep- } \\
\text { tion of [the manufacturer brand]. } \\
\text { Through his Facebook post and blog, [the sabo- } \\
\text { teur] tries to draw people's attention on the mis- } \\
\text { behavior of [the manufacturer brand]. }\end{array}$ & .76 & .81 & .78 & .80 & .71 & .80 \\
\hline $\begin{array}{l}\text { Value-based } \\
\text { CBS }^{\text {b }}\end{array}$ & $\begin{array}{l}\text { The scenario described by [the saboteur] mainly } \\
\text { addresses the personal values [of the saboteur]. } \\
\text { The behavior of [the manufacturer brand] de- } \\
\text { scribed by [the saboteur] mainly violates the per- } \\
\text { sonal values of [the saboteur]. }\end{array}$ & .83 & .88 & .75 & .82 & .88 & .90 \\
\hline $\begin{array}{l}\text { Performance- } \\
\text { based CBS }\end{array}$ & $\begin{array}{l}\text { The scenario described by [the saboteur] mainly } \\
\text { addresses the [manufacturer brand]'s perfor- } \\
\text { mance. } \\
\text { The behavior of [the manufacturer brand] de- } \\
\text { scribed by [the saboteur] mainly contradicts [the } \\
\text { saboteur]'s expectations regarding the [manufac- } \\
\text { turer brand]'s performance. }\end{array}$ & .85 & .89 & .80 & .70 & .89 & .86 \\
\hline $\begin{array}{l}\text { Personal value } \\
\text { conflict }^{\mathrm{b}}\end{array}$ & $\begin{array}{l}\text { The behavior of [the manufacturer brand] de- } \\
\text { scribed by [the saboteur]... } \\
\ldots \text { violates my personal values. } \\
\text {...contradicts my personal values. } \\
\text {...is ethically questionable in my eyes. }\end{array}$ & - & .84 & - & .86 & - & - \\
\hline
\end{tabular}

\footnotetext{
${ }^{a}$ measured with a 7-point semantic differential scale

${ }^{\mathrm{b}}$ measured with a 7-point Likert scale anchored by $1=$ "strongly disagree," $7=$ "strongly agree"

${ }^{c}$ measured with a single choice option

${ }^{\mathrm{d}}$ measured with a single item in pretest 1 and 2
} 
Table B.1 (Continued). Constructs Indicators, Measurement Items, Scale Reliabilities Studies 1-3

\begin{tabular}{|c|c|c|c|c|c|c|c|}
\hline \multirow[t]{2}{*}{$\overline{\text { Measure }}$} & \multirow[t]{2}{*}{ Items } & \multicolumn{6}{|c|}{ 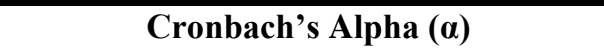 } \\
\hline & & $\begin{array}{l}\text { Pretest } \\
\text { S1 }\end{array}$ & $\begin{array}{l}\text { Study } \\
1\end{array}$ & $\begin{array}{l}\text { Pretest } \\
\quad \text { S2 }\end{array}$ & $\begin{array}{l}\text { Study } \\
2\end{array}$ & $\begin{array}{l}\text { Pretest } \\
\text { S3 }\end{array}$ & $\begin{array}{c}\text { Study } \\
3\end{array}$ \\
\hline $\begin{array}{l}\text { Assortment } \\
\text { decision }^{c}\end{array}$ & $\begin{array}{l}\text { The retailer X delists [the manufacturer brand] } \\
\text { from its assortment (the retailer does no longer } \\
\text { offer [the manufacturer brand] to its customers). } \\
\text { The retailer X continues to carry [the manufac- } \\
\text { turer brand] in its assortment (the retailer contin- } \\
\text { ues to offer [the manufacturer brand] to its cus- } \\
\text { tomers). } \\
\text { I don't know. }\end{array}$ & - & - & - & - & - & - \\
\hline \multicolumn{8}{|l|}{ Dependent Variable } \\
\hline $\begin{array}{l}\text { Attitude toward the } \\
\text { retailer brand }{ }^{\text {a }}\end{array}$ & $\begin{array}{l}\text { unappealing (1)-appealing (7) } \\
\text { bad (1)-good (7) } \\
\text { unpleasant (1)-pleasant (7) } \\
\text { unfavorable (1)-favorable (7) } \\
\text { unlikable (1)-likable (7) }\end{array}$ & - & .96 & - & .96 & - & .96 \\
\hline \multicolumn{8}{|l|}{ Mediating Variable } \\
\hline Fairness ${ }^{b}$ & $\begin{array}{l}\text { The assortment decision of [the retailer brand] } \\
\text { was... } \\
\text {...fair. } \\
\text {...ethically correct. }\end{array}$ & - & - & - & .86 & - & - \\
\hline \multicolumn{8}{|c|}{ Moderating Variables } \\
\hline $\begin{array}{l}\text { Benevolent sexism } \\
\text { inventory }{ }^{b}\end{array}$ & $\begin{array}{l}\text { Many women have a quality of purity that few } \\
\text { men possess. } \\
\text { Women should be cherished and protected by } \\
\text { men. } \\
\text { Every man ought to have a woman whom he } \\
\text { adores. } \\
\text { Men are incomplete without women. } \\
\text { Women, compared to men, tend to have a supe- } \\
\text { rior moral sensibility. } \\
\text { Men should be willing to sacrifice their own } \\
\text { wellbeing in order to provide financially for the } \\
\text { women in their lives. }\end{array}$ & - & - & - & - & - & .74 \\
\hline
\end{tabular}

\footnotetext{
${ }^{a}$ measured with a 7-point semantic differential scale

${ }^{\mathrm{b}}$ measured with a 7-point Likert scale anchored by $1=$ "strongly disagree," $7=$ "strongly agree"

${ }^{c}$ measured with a single choice option

${ }^{\mathrm{d}}$ measured with a single item in pretest 1 and 2
} 
Table B.1 (Continued). Constructs Indicators, Measurement Items, Scale Reliabilities Studies 1-3

\begin{tabular}{|c|c|c|c|c|c|c|c|}
\hline \multirow[t]{2}{*}{ Measure } & \multirow[t]{2}{*}{ Items } & \multicolumn{6}{|c|}{ Cronbach's Alpha (a) } \\
\hline & & $\begin{array}{l}\text { Pretest } \\
\text { S1 }\end{array}$ & $\begin{array}{c}\text { Study } \\
1\end{array}$ & $\begin{array}{l}\text { Pretest } \\
\text { S2 }\end{array}$ & $\begin{array}{l}\text { Study } \\
2\end{array}$ & $\begin{array}{l}\text { Pretest } \\
\text { S3 }\end{array}$ & $\begin{array}{c}\text { Study } \\
3\end{array}$ \\
\hline $\begin{array}{l}\text { Quality conscious- } \\
\text { ness }{ }^{\text {b }}\end{array}$ & $\begin{array}{l}\text { Getting very good quality is very important to } \\
\text { me. } \\
\text { When it comes to purchasing products, I try to } \\
\text { get the very best or perfect choice. } \\
\text { In general, I usually try to buy the best overall } \\
\text { quality. } \\
\text { I make special effort to choose the very best } \\
\text { quality products. }\end{array}$ & - & - & - & - & - & .88 \\
\hline \multicolumn{8}{|l|}{ Control Variables } \\
\hline Credibility ${ }^{a}$ & $\begin{array}{l}\text { The described incidents with the retailer } \mathrm{X} \text { and } \\
\text { the manufacturer brand } \mathrm{Y} \text { were... } \\
\text {...very incredible. (1) - ...very credible. ( } 7 \text { ) } \\
\text {...very unrealistic. (1) -...very realistic. (7) }\end{array}$ & .86 & - & .78 & - & .97 & - \\
\hline Failure severity $^{a}$ & $\begin{array}{l}\text { The failures caused... } \\
\text {...minor problems. (1)-...major problems. ( } 7) \\
\text {...small inconveniences. (1)-...big inconven- } \\
\text { iences. (7) } \\
\text {...minor aggravation. (1)-...major aggravation. } \\
\text { (7) }\end{array}$ & .94 & - & .93 & - & .93 & - \\
\hline Dissatisfaction $^{\mathrm{b}}$ & $\begin{array}{l}\text { Due to the failures, I felt... } \\
\text {...dissatisfied. } \\
\text {...displeased. } \\
\text {...discontented. }\end{array}$ & .71 & - & .96 & - & .89 & - \\
\hline Blame attribution ${ }^{b}$ & $\begin{array}{l}\text { I believe that [the manufacturer brand] was re- } \\
\text { sponsible for the failure. } \\
\text { Overall, the failure was [the manufacturer } \\
\text { brand]'s fault. } \\
\text { I blame [the manufacturer brand] for what hap- } \\
\text { pened. }\end{array}$ & .84 & - & .95 & - & .97 & - \\
\hline Unfairness ${ }^{b}$ & $\begin{array}{l}\text { The behavior of [the manufacturer brand] was... } \\
\text {...unfair. }{ }^{\mathrm{d}} \\
\text {...immoral. }\end{array}$ & - & 一 & 一 & - & .80 & - \\
\hline Retailer image $^{\text {a }}$ & $\begin{array}{l}\text { [The retailer] is close to customers. } \\
\text { [The retailer] offers good quality products. } \\
\text { [The retailer] has pleasant stores. } \\
\text { [The retailer] offers good value for money. }\end{array}$ & .91 & - & .76 & - & - & - \\
\hline
\end{tabular}

\footnotetext{
${ }^{a}$ measured with a 7-point semantic differential scale

${ }^{\mathrm{b}}$ measured with a 7-point Likert scale anchored by $1=$ "strongly disagree," $7=$ "strongly agree"

${ }^{\mathrm{c}}$ measured with a single choice option

${ }^{\mathrm{d}}$ measured with single item in pretest 1 and 2
} 
TABLE B.2. Manipulation Checks for Studies 1 and 2 with Full-Factorial Anova Models

\begin{tabular}{|c|c|c|c|c|}
\hline \multirow[t]{2}{*}{ Measure } & \multicolumn{2}{|r|}{ Study 1} & \multicolumn{2}{|r|}{ Study 2} \\
\hline & EMM (SE) & Test Statistic, p-value & EMM (SE) & Test Statistic, p-value \\
\hline \multicolumn{5}{|l|}{ Manipulation Checks } \\
\hline \multicolumn{5}{|l|}{ Performance-Based CBS } \\
\hline Assortment Decision & & $\mathrm{F}(1,431)=.82, \mathrm{p}=.37$ & & $F(1,378)=1.25, p=.26$ \\
\hline Continuation & $4.45(.10)$ & & $4.56(.10)$ & \\
\hline Delisting & $4.32(.09)$ & & $4.40(.11)$ & \\
\hline CBS Type & & $F(1,431)=720.34, p=.000$ & & $\mathrm{~F}(1,378)=219.04, \mathrm{p}=.000$ \\
\hline Performance-Based CBS & $6.20(.09)$ & & $5.57(.10)$ & \\
\hline Value-Based CBS & $2.57(.10)$ & & $3.39(.10)$ & \\
\hline Assortment Size & & $\mathrm{F}(1,431)=.11, \mathrm{p}=.74$ & & $\mathrm{~F}(1,378)=.81, \mathrm{p}=.37$ \\
\hline Narrow & $4.41(.09)$ & & $4.41(.11)$ & \\
\hline Large & $4.36(.10)$ & & $4.54(.10)$ & \\
\hline \multicolumn{5}{|l|}{ Value-Based CBS } \\
\hline Assortment Decision & & $\mathrm{F}(1,431)=1.18, \mathrm{p}=.28$ & & $\mathrm{~F}(1,378)=1.92, \mathrm{p}=.17$ \\
\hline Continuation & $5.01(.11)$ & & $5.10(.11)$ & \\
\hline Delisting & $5.18(.11)$ & & $5.32(.11)$ & \\
\hline CBS Type & & $\mathrm{F}(1,431)=229.61, \mathrm{p}=.000$ & & $\mathrm{~F}(1,378)=39.27, \mathrm{p}=.000$ \\
\hline Performance-Based CBS & $3.91(.11)$ & & $4.71(.11)$ & \\
\hline Value-Based CBS & $6.28(.11)$ & & $5.71(.11)$ & \\
\hline Assortment Size & & $\mathrm{F}(1,431)=2.25, \mathrm{p}=.13$ & & $\mathrm{~F}(1,378)=.06, \mathrm{p}=.80$ \\
\hline Narrow & $5.21(.11)$ & & $5.19(.12)$ & \\
\hline Large & $4.98(.12)$ & & $5.23(.11)$ & \\
\hline
\end{tabular}

Note. EMM = estimated marginal mean; $\mathrm{SE}=$ standard error. 
TABLE B.2 (Continued). Manipulation Checks for Studies 1 and 2 with Full-Factorial Anova Models

\begin{tabular}{|c|c|c|c|c|}
\hline \multirow[t]{2}{*}{ Measure } & \multicolumn{2}{|r|}{ Study 1} & \multicolumn{2}{|r|}{ Study 2} \\
\hline & EMM (SE) & Test Statistic, p & EMM (SE) & Test Statistic, p \\
\hline \multicolumn{5}{|l|}{ Assortment Size } \\
\hline Assortment Decision & & $\mathrm{F}(1,431)=.81, \mathrm{p}=.37$ & & $\mathrm{~F}(1,378)=.65, \mathrm{p}=.42$ \\
\hline Continuation & $4.08(.09)$ & & $4.35(.09)$ & \\
\hline Delisting & $4.19(.09)$ & & $4.25(.09)$ & \\
\hline CBS Type & & $\mathrm{F}(1,431)=.51, \mathrm{p}=.48$ & & $\mathrm{~F}(1,378)=2.24, \mathrm{p}=.14$ \\
\hline Performance-Based CBS & $4.18(.09)$ & & $4.39(.09)$ & \\
\hline Value-Based CBS & $4.09(.09)$ & & $4.21(.09)$ & \\
\hline Assortment Size & & $\mathrm{F}(1,431)=588.77, \mathrm{p}=.000$ & & $\mathrm{~F}(1,378)=798.41, \mathrm{p}=.000$ \\
\hline Narrow & $2.62(.08)$ & & $2.55(.09)$ & \\
\hline Large & $5.64(.09)$ & & $6.05(.09)$ & \\
\hline
\end{tabular}

Note. EMM = estimated marginal mean; SE = standard error. 
Table B.3. Manipulation Checks for Studies 1 and 2 with Full-Factorial Binary Logistic Regression Models

\begin{tabular}{|c|c|c|c|c|c|c|c|c|}
\hline \multirow[t]{2}{*}{ Measure } & \multicolumn{4}{|c|}{ Study 1} & \multicolumn{4}{|c|}{ Study 2} \\
\hline & 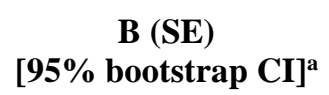 & $\begin{array}{l}\text { Wald } \chi^{2} \\
\quad(\text { df })\end{array}$ & p-value & $\begin{array}{c}\exp (B) \\
{[95 \% \text { CI }]^{b}}\end{array}$ & $\begin{array}{c}\text { B }(\mathrm{SE}) \\
{\left[95 \%{\text { bootstrap } \mathrm{CI}]^{\mathrm{a}}}^{\mathrm{a}}\right.}\end{array}$ & Wald $\chi^{2}(\mathrm{df})$ & p-value & $\begin{array}{c}\exp (B) \\
{[95 \% C I]^{b}}\end{array}$ \\
\hline \multicolumn{9}{|l|}{ Manipulation Checks } \\
\hline \multicolumn{9}{|l|}{ Assortment Decision } \\
\hline Constant & $\begin{array}{c}-3.15(.55) \\
{[-4.91,-2.30]}\end{array}$ & $33.52(1)$ & .000 & .04 & $\begin{array}{c}-5.32(1.25) \\
{[-50.52,-3.77]}\end{array}$ & $18.17(1)$ & .000 & .01 \\
\hline Assortment Decision & $\begin{array}{c}8.64(1.07) \\
{[7.43,40.25]}\end{array}$ & $65.60(1)$ & .000 & $\begin{array}{c}5622.62 \\
{[695.78,45436.56]}\end{array}$ & $\begin{array}{c}9.38(1.16) \\
{[8.04,55.43]}\end{array}$ & $65.42(1)$ & .000 & $\begin{array}{c}11814.43 \\
{[1217.79,114618.55]}\end{array}$ \\
\hline CBS Type & $\begin{array}{c}-.04(.69) \\
{[-1.76,1.46]}\end{array}$ & $.00(1)$ & .96 & $\begin{array}{c}.96 \\
{[.25,3.69]}\end{array}$ & $\begin{array}{c}1.20(1.16) \\
{[-1.22,17.74]}\end{array}$ & $1.07(1)$ & .30 & $\begin{array}{c}3.32 \\
{[.34,32.23]}\end{array}$ \\
\hline Assortment Size & $\begin{array}{c}-.15(.69) \\
{[-2.10,1.45]}\end{array}$ & $.05(1)$ & .82 & $\begin{array}{c}.86 \\
{[.22,3.29]}\end{array}$ & $\begin{array}{c}.03(1.01) \\
{[-16.92,17.08]}\end{array}$ & $.00(1)$ & .98 & $\begin{array}{c}1.03 \\
{[.14,7.41]}\end{array}$ \\
\hline & \multicolumn{4}{|c|}{$\begin{array}{c}\mathrm{R}^{2}=.87 \text { (Hosmer \& Lemeshow), } .70(\text { Cox \& Snell }) \\
.93 \text { (Nagelkerke). Model } \chi 2(3)=518.18, \mathrm{p}<.001\end{array}$} & \multicolumn{4}{|c|}{$\begin{array}{l}\mathrm{R}^{2}=.92 \text { (Hosmer \& Lemeshow), } .72(\text { Cox \& Snell }) \\
.96 \text { (Nagelkerke). Model } \chi 2(3)=484.99, \mathrm{p}<.001\end{array}$} \\
\hline
\end{tabular}

Note. $\mathrm{B}=$ unstandardized regression coefficients; $\mathrm{SE}=$ standard error; Wald $\chi^{2}=$ Wald chi-square; $\mathrm{df}=\mathrm{degrees}$ of freedom; exp $(\mathrm{B})=$ odds ratio for binary logistic regression models.

a $95 \%$ bias corrected and accelerated bootstrap confidence interval based on 1000 samples

b $95 \%$ confidence interval for odds ratio 
Table B.4. Baseline Effects of a Sabotaged Manufacturer Brand on the Attitude toward Retailer Brand that Carries It for Studies 1-3

\begin{tabular}{|c|c|c|c|c|c|c|}
\hline \multirow[t]{2}{*}{ Measure } & \multicolumn{2}{|r|}{ Study 1} & \multicolumn{2}{|r|}{ Study 2} & \multicolumn{2}{|r|}{ Study 3} \\
\hline & M (SE) & Test Statistic, p-value & M (SE) & Test Statistic, p-value & $\mathbf{M}(\mathbf{S E})$ & Test Statistic, p-value \\
\hline \multicolumn{7}{|c|}{$\begin{array}{l}\text { Baseline Effects of } \\
\text { CBS }\end{array}$} \\
\hline Brand Attitude & & $\mathrm{F}(1,172)=63.21, \mathrm{p}=.000$ & & $F(1,191)=81.08, p=.000$ & & $F(1,279)=27.39, p=.000$ \\
\hline Control Group & $4.97(.13)$ & & $5.41(.10)$ & & $5.41(.08)$ & \\
\hline CBS & $3.76(.08)$ & & $4.30(.07)$ & & $4.90(.06)$ & \\
\hline
\end{tabular}

Note. $\mathrm{M}=$ mean; $\mathrm{SE}=$ standard error. 
Table B.5. Consumers' Attitude toward the Retailer Brand after Delisting versus Continuing the Sabotaged Manufacturer Brand as Main Effect and by CBS Type and Assortment Size with Full-Factorial Anova Models for Study 1 and 2

\begin{tabular}{|c|c|c|c|c|}
\hline \multirow[t]{2}{*}{ Measure } & \multicolumn{3}{|c|}{ Study 1} & \multirow{2}{*}{$\begin{array}{c}\text { Study } 2 \\
\text { Test Statistic, p }\end{array}$} \\
\hline & EMM (SE) & Test Statistic, p & EMM (SE) & \\
\hline $\begin{array}{l}\text { Main Effect of } \\
\text { Assortment Decision }\end{array}$ & & $\mathrm{F}(1,431)=36.91, \mathrm{p}=.000$ & & $\mathrm{~F}(1,378)=32.76, \mathrm{p}=.000$ \\
\hline Continuation & $3.32(.11)$ & & $3.94(.10)$ & \\
\hline Delisting & $4.20(.10)$ & & $4.73(.10)$ & \\
\hline $\begin{array}{l}\text { Two-Way Interaction of Assortment Deci- } \\
\text { sion and CBS Type }\end{array}$ & & $\mathrm{F}(1,431)=6.12, \mathrm{p}=.01$ & & $\mathrm{~F}(1,378)=14.00, \mathrm{p}=.000$ \\
\hline \multicolumn{5}{|l|}{ Performance-Based CBS } \\
\hline Continuation & $3.36(.14)$ & & $4.16(.14)$ & \\
\hline Delisting & $3.88(.14)$ & & $4.43(.14)$ & \\
\hline \multicolumn{5}{|l|}{ Value-Based CBS } \\
\hline Continuation & $3.28(.16)$ & & $3.71(.14)$ & \\
\hline Delisting & $4.52(.15)$ & & $5.03(.14)$ & \\
\hline
\end{tabular}

Note. $\mathrm{EMM}=$ estimated marginal mean; $\mathrm{SE}=$ standard error. 
Table B.5 (Continued). Consumers' Attitude toward the Retailer Brand after Delisting versus Continuing the Sabotaged Manufacturer Brand as Main Effect and by CBS Type and Assortment Size with Full-Factorial Anova Models for Study 1 and 2

\begin{tabular}{|c|c|c|c|c|}
\hline \multirow[b]{2}{*}{ Measure } & \multicolumn{2}{|c|}{ Study 1} & \multicolumn{2}{|c|}{ Study 2} \\
\hline & EMM (SE) & Test Statistic, $\mathbf{p}$ & EMM (SE) & Test Statistic, p \\
\hline $\begin{array}{l}\text { Three-Way Interaction of Assort- } \\
\text { ment Decision, CBS Type and As- } \\
\text { sortment Size }\end{array}$ & & $\mathrm{F}(1,431)=3.93, \mathrm{p}=.048$ & & $\mathrm{~F}(1,378)=6.89, \mathrm{p}=.01$ \\
\hline \multicolumn{5}{|l|}{ Narrow Assortment } \\
\hline \multicolumn{5}{|l|}{ Performance-Based CBS } \\
\hline Continuation & $3.48(.19)$ & & $4.24(.20)$ & \\
\hline Delisting & $3.60(.19)$ & & $4.10(.21)$ & \\
\hline \multicolumn{5}{|l|}{ Value-Based CBS } \\
\hline Continuation & $3.14(.22)$ & & $3.62(.20)$ & \\
\hline Delisting & $4.56(.19)$ & & $5.25(.20)$ & \\
\hline \multicolumn{5}{|l|}{ Broad Assortment } \\
\hline \multicolumn{5}{|l|}{ Performance-Based CBS } \\
\hline Continuation & $3.24(.21)$ & & $4.08(.18)$ & \\
\hline Delisting & $4.18(.21)$ & & $4.77(.20)$ & \\
\hline \multicolumn{5}{|l|}{ Value-Based CBS } \\
\hline Continuation & $3.41(.21)$ & & $3.81(.20)$ & \\
\hline Delisting & $4.49(.22)$ & & $4.81(.18)$ & \\
\hline
\end{tabular}

Note. $\mathrm{EMM}=$ estimated marginal mean; $\mathrm{SE}=$ standard error. 
Table B.6. Regression Coefficients, Standard Errors, and Model Summary Information for the Moderated Moderated Mediation Model for Study 2

\begin{tabular}{|c|c|c|c|c|c|c|c|c|}
\hline \multirow[b]{3}{*}{ Antecedent } & \multicolumn{8}{|c|}{ Consequent } \\
\hline & & \multicolumn{3}{|c|}{ Perceived Fairness $(\mathrm{M})$} & & \multicolumn{3}{|c|}{ Attitude Toward the Retailer Brand (Y) } \\
\hline & & Coeff. & SE & p-value & & Coeff. & SE & p-value \\
\hline Assortment Decision (X) & $a_{1}$ & .06 & .34 & .87 & $c^{\prime}$ & .14 & .14 & .31 \\
\hline Perceived Fairness (M) & & - & - & - & $b$ & .44 & .04 & .00 \\
\hline CBS Type (W) & $a_{2}$ & -1.55 & .31 & .00 & & - & - & - \\
\hline Assortment Size (Z) & $a_{3}$ & .03 & .33 & .92 & & - & - & - \\
\hline $\mathrm{X} \times \mathrm{W}$ & $a_{4}$ & 2.98 & .44 & .00 & & - & - & - \\
\hline $\mathrm{X} \times \mathrm{Z}$ & $a_{5}$ & .63 & .46 & .17 & & - & - & - \\
\hline $\mathrm{W} \times \mathrm{Z}$ & $a_{6}$ & .49 & .46 & .29 & & & & \\
\hline $\mathrm{X} \times \mathrm{W} \times \mathrm{Z}$ & $a_{7}$ & -1.39 & .63 & .03 & & & & \\
\hline \multirow[t]{3}{*}{ Constant } & $\mathrm{i}_{1}$ & 4.14 & .24 & .00 & $\mathrm{i}_{2}$ & 2.40 & .15 & .00 \\
\hline & \multicolumn{4}{|c|}{$\mathrm{R}^{2}=.29$} & & \multicolumn{3}{|c|}{$\mathrm{R}^{2}=.33$} \\
\hline & \multicolumn{4}{|c|}{$\mathrm{F}(7,378)=25.19, p<.001$} & & \multicolumn{3}{|c|}{$\mathrm{F}(2,383)=89.75, p<.001$} \\
\hline
\end{tabular}

Note. Coeff. = unstandardized regression coefficients; $\mathrm{SE}=$ standard error. PROCESS models were calculated with the HC3 estimator, which means that all standard errors for continuous outcome models were based on the hc3 estimator. 
Table B.7. Regression Coefficients, Standard Errors, and Model Summary Information for the Moderation Model for Study 3

\begin{tabular}{|c|c|c|c|c|c|}
\hline & & Coeff. & $\mathrm{SE}$ & t-value & p-value \\
\hline Intercept & $i_{1}$ & 4.66 & .36 & 12.82 & .00 \\
\hline Assortment Decision (X) & $b_{1}$ & .80 & .55 & 1.45 & .15 \\
\hline CBS Type (M) & $b_{2}$ & -1.25 & .51 & -2.43 & .02 \\
\hline Benevolent Sexism Inventory (W) & $b_{3}$ & -.02 & .11 & -.24 & .81 \\
\hline $\mathrm{X} \times \mathrm{M}$ & $b_{4}$ & 1.38 & .72 & 1.91 & .06 \\
\hline $\mathrm{X} \times \mathrm{W}$ & $b_{5}$ & -.05 & .15 & -.31 & .76 \\
\hline $\mathrm{M} \times \mathrm{W}$ & $b_{6}$ & .37 & .14 & 2.69 & .01 \\
\hline $\mathrm{X} \times \mathrm{M} \times \mathrm{W}$ & $b_{7}$ & -.43 & .19 & -2.26 & .02 \\
\hline & & & \multicolumn{3}{|c|}{$\mathrm{R}^{2}=.07$} \\
\hline & & & \multicolumn{3}{|c|}{$\mathrm{F}(7,537)=5.19, p<.001$} \\
\hline
\end{tabular}

Note. Coeff. = unstandardized regression coefficients; SE = standard error. PROCESS models were calculated with the HC3 estimator, which means that all standard errors for continuous outcome models were based on the hc3 estimator. 
Table B.8. Regression Coefficients, Standard Errors, and Model Summary Information for the Moderation Model for Study 3

\begin{tabular}{|c|c|c|c|c|c|}
\hline & & Coeff. & $\mathrm{SE}$ & t-value & p-value \\
\hline Intercept & $i_{1}$ & 4.39 & .61 & 7.20 & .00 \\
\hline Assortment Decision (X) & $b_{1}$ & -.33 & .90 & -.37 & .71 \\
\hline CBS Type (M) & $b_{2}$ & -2.01 & .78 & -2.58 & .01 \\
\hline Quality Consciousness (W) & $b_{3}$ & .04 & .12 & .31 & .76 \\
\hline $\mathrm{X} \times \mathrm{M}$ & $b_{4}$ & 2.37 & 1.11 & 2.12 & .03 \\
\hline $\mathrm{X} \times \mathrm{W}$ & $b_{5}$ & .18 & .17 & 1.06 & .29 \\
\hline $\mathrm{MxW}$ & $b_{6}$ & .39 & .15 & 2.68 & .01 \\
\hline $\mathrm{X} \times \mathrm{M} \times \mathrm{W}$ & $b_{7}$ & -.48 & .21 & -2.25 & .02 \\
\hline \multicolumn{6}{|c|}{$\mathrm{R}^{2}=.08$} \\
\hline & & & \multicolumn{3}{|c|}{$\mathrm{F}(7,537)=7.09, p<.001$} \\
\hline
\end{tabular}

Note. Coeff. $=$ unstandardized regression coefficients; SE $=$ standard error. PROCESS models were calculated with the HC3 estimator, which means that all standard errors for continuous outcome models were based on the hc3 estimator. 


\section{References}

Bolton, Lisa E., Hean Tat Keh, and Joseph W. Alba (2010), "How Do Price Fairness Perceptions Differ Across Culture?," Journal of Marketing Research, 47 (3), 564-76.

Bonifield, Carolyn, and Catherine Cole (2007), “Affective Responses to Service Failure: Anger, Regret, and Retaliatory versus Conciliatory Responses,” Marketing Letters, 18 (1-2), 85-99.

Grégoire, Yany, and Robert J. Fisher (2008), “Customer Betrayal and Retaliation: When Your Best Customers Become Your Worst Enemies," Journal of the Academy of Marketing Science, 36 (2), 247-61.

— Daniel Laufer, and Thomas M. Tripp (2010), “A Comprehensive Model of Customer Direct and Indirect Revenge: Understanding the Effects of Perceived Greed and Customer Power," Journal of the Academy of Marketing Science, 38 (6), 738-58.

Hayes, Andrew F. (2013), Introduction to Mediation, Moderation, and Conditional Process Analysis: A Regression-Based Approach, New York: Guilford Press.

Kremer, Florence, and Catherine Viot (2012), "How Store Brands Build Retailer Brand Image," International Journal of Retail and Distribution Management, 40 (7), 528-43.

Rollero, Chiara, Peter Glick, and Stefano Tartaglia (2014), "Psychometric Properties of Short Versions of the Ambivalent Sexism Inventory and Ambivalence Toward Men Inventory," TPM: Testing, Psychometrics, Methodology in Applied Psychology, 21 (2), 149-59.

Shim, Soyeon, and Kenneth C. Gehrt (1996), "Hispanic and Native American Adolescents: An Exploratory Study of Their Approach to Shopping," Journal of Retailing, 72 (3), 307-24. 